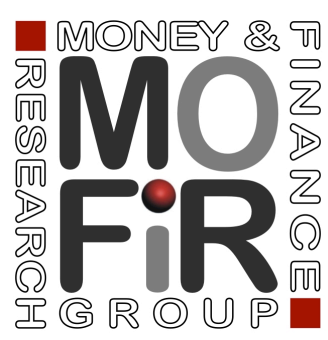

\title{
REGULATION, FINANCIAL CRISES, AND LIBERALIZATION TRAPS
}

Francesco Marchionne Beniamino Pisicoli Michele Fratianni

Working paper no. 143

November 2017 


\title{
Regulation, financial crises, and liberalization traps
}

\author{
Francesco Marchionne ${ }^{\mathrm{a}}$ \\ Beniamino Pisicoli ${ }^{\mathrm{b}}$ \\ Michele Fratiannic
}

\begin{abstract}
$\underline{\text { Abstract }}$
To reconcile the mixed results emerging from the empirical literature, we first develop a theoretical model whose main implication is a concave impact of regulation on the probability of a crisis, and then we test this relationship by applying a Probit model of a non-linear specification to annual data from 1999 to 2011 drawn from 132 countries. Our key inference is that the probability of a financial crisis fits an inverted U-shaped curve: it rises as regulation stringency moves from low to medium levels and falls from medium to high levels. Countries located at the intermediate level of regulatory stringency face more financial instability than countries that are either loosely or severely regulated. We identify the latter two groups as falling in "liberalization traps". Institutional quality interacts significantly with the regulatory environment, implying trade-offs between regulatory stringency and institutional quality.
\end{abstract}

JEL Classification: G01, G21, G28.

Keywords: crisis, banks, institutions, liberalization, regulation

\footnotetext{
${ }^{a}$ (corresponding author) Indiana University, Kelley School of Business, 1309 E. $10^{\text {th }}$ Street, Bloomington, Indiana 47405, USA; Money and Finance Research Group (MoFiR); fmarchio@indiana.edu

${ }^{\mathrm{b}}$ University of Bari, Dipartimento di Scienze Economiche e Metodi Matematici, Largo Abbazia S.Scolastica (ex via C.Rosalba 53), 70124 Bari (Italy); ben.pisicoli@gmail.com.

${ }^{\mathrm{c}}$ Indiana University, Kelley School of Business, 1309 E. $10^{\text {th }}$ Street, Bloomington, Indiana 47405, USA; Univerità Politecnica delle Marche, School of Business Giorgio Fuà, Piazza Martelli 8, Ancona (Italy); Money and Finance Research Group (MoFiR); fratiann@indiana.edu
}

Acknowledgement: We thank Rachael Dillon, Yannick Lucotte, Giuseppe Coco, Laura Serlenga, Annalisa Vinella for comments and suggestions. 


\section{INTRODUCTION}

Financial regulation is prone to big swings. Over almost a century, there have been two big peaks of financial regulation, the first in the wake of Great Depression of the 1930s and the second after the Great Financial Crisis of 2008-2009. Between these two regulatory peaks, we have gone through a long wave of deregulation that started in the 1980s in the industrial countries and moved to the developing countries in the 1990s. This deregulation preceded financial crises. Bordo et al. (2001) show that crisis frequency doubled after the collapse of Bretton Woods in 1973. Many developing countries that deregulated in the 1990s soon had to contend with banks' insolvency, currency crises and difficulties in financing government deficits (Daniel and Jones, 2007; Abiad et al., 2010). A more liberal financial environment, including freer capital mobility, preceded most banking crises. Kaminsky and Reinhart (1999) find that in their sample liberalization occurred before the eruption of crises in approximately 70 percent of banking crisis episodes (see also Reinhart and Rogoff, 2008: Fig. 10.1).

In sum, the temporal relationship between (de)regulation and crises is not uniform throughout history. Over relatively short time windows, the timing sequence can be either first regulation and then crisis or first crisis and then regulation. But in the vast majority of cases regulation determines the environment in which banks operate; that is, crisis is a left-hand side variable and regulation sits on the right-hand side of a testable equation. ${ }^{1}$ This is the conclusion of the empirical literature.

As to the impact of regulation on the probability of a crisis, three broad findings emerge. The first is that the initial works suggest a negative effect of regulation on financial stability. Banking crises are more frequent in countries with a sharper divide between investment and commercial banks and greater asset restrictions placed on commercial banks (Barth et al.,

\footnotetext{
${ }^{1}$ A regulatory environment should not be confused with the ability of the authorities to effectively regulate financial firms, as it is claimed by adherents of the efficient market paradigm (Shaw, 1973; McKinnon, 1973).
} 
2001). Furthermore, the impact varies according to the regulation channel. Barth et al. (2004) report that only higher bank asset restrictions, greater foreign-banks entry barriers, and deposit insurance schemes increase financial instability. In general, tighter restrictions and government interventions are associated with more vulnerable financial systems (e.g. Lee et al., 2016; Goetz, 2017; Lambert et al., 2017). However, a growing literature is struggling to find conclusive results. For example, using a sample of 113 developing countries, Zazzaro et al. (2015) show that financial reforms included in the intervention package of the International Monetary Fund can prevent crises. On the other hand, Lee and $\mathrm{Lu}$ (2015) conclude that only a more stringent capital regulation and greater entry requirements lower the ratio of nonperforming loans to gross loans and promote a more stable financial sector.

The second feature is that empirical findings are sensitive to the measure of banking regulation. Sundararajan et al. (2001) find no direct relationship between financial stability and the application of the Core Principles for Effective Bank Supervision (BCPs) issued by the Basel Committee on Banking Supervision. In contrast, Podpiera (2006) concludes that a higher compliance to $B C P s$ decreases the percentage of non-performing loans. The positive effect is confirmed also by an improvement in Moody's ratings (Demirgüç-Kunt et al., 2008). After separating the various dimensions of the Principles, only compliance with $B C P$ No. 21 is positively related to bank soundness, a result in line with findings on regulation channels. Extending their earlier study, Demirgüç-Kunt et al. (2010) fail to uncover that a higher compliance to $B C P s$ affects bank soundness and risk. In sum, findings on bank stability are sensitive to $B C P$ measures.

Lastly, results are ambiguous, not only for industrial countries, but also for developing countries. Berger at al. (2016) show that regulatory interventions reduced risky banking practices and affected liquidity creation on the liability side in Germany over the period 19992009. Barrell et al. (2010) confirm the lower procyclicality associated with higher levels of 
capital and liquidity regulation among OECD countries. ${ }^{2}$ In contrast, Fratzscher et al. (2016) find that tighter post-crisis capital regulation curtailed domestic credit growth and lowered banking stability when focusing on their OECD countries subsample. Unexpectedly, findings are not clearer moving to developing countries. Tchana Tchana (2014) finds mixed effects applying a Markov-switching model to the Indonesian banking sector. Results indicate that, while entry restrictions, deposit insurance and capital requirements reduce the probability and the duration of a banking crisis, larger reserve requirements raise them. Similarly, focusing on non-industrial economies, Klomp and de Haan (2014) show that stricter regulation reduces bank riskiness, thus improving financial stability. However, the impact of liquidity regulation and activity restrictions on bank risk greatly depends on country-specific institutional quality.

In an effort to avoid the influence that different measures and research approaches may have on outcomes, a recent and growing literature has employed the Heritage Foundation Financial Freedom Index $(F F I)$ as an inverted proxy of banking regulation (e.g., González 2005, OECD 2006). Focusing on 251 banks from 36 countries, González (2005) concludes that a lower value of FFI encourages banks to undertake riskier strategies. Chortareas et al. (2013), who investigate a large sample of EU commercial banks, uncover similar findings, namely that the higher is $F F I$, the higher is bank efficiency, particularly in politically freer countries. Conversely, extending the sample to 4,333 banks drawn from 83 countries, Cubillas and Gonzalez (2014) show that financial liberalization promotes banks competition in developed countries, but expands risk-taking opportunities in developing countries. Capital requirements, supervision, and financial transparency mitigate in part this effect. ${ }^{3}$

\footnotetext{
${ }^{2}$ Ambiguity persists even when regulation interacts with competition. For instance, Beck et al. (2013) reveal a significantly negative interaction between competition, stricter activity restrictions and more generous deposit insurance on banks' fragility, while Anginer et al. (2014) find that more stringent capital requirements and greater supervision increase stability, while competition is irrelevant.

${ }^{3}$ Results are clearer when using the economic freedom instead of the financial freedom index. With a sample of 175 countries covering the period 1993-2010, Bjornskov (2016) concludes that regulatory components of the economic freedom index are associated with smaller peak-to-trough ratios and shorter recovery time.
} 
In sum, the general thrust of the empirical literature is that there is some evidence pointing to regulation exerting a negative impact on financial stability, but results are far from being conclusive and do not improve as one moves from specific measures to general proxies or by focusing exclusively on developed or developing countries.

With this background, our paper starts by developing a model whose main implication is that the probability of a crisis is best described by a concave curve with respect to an investment in regulation. The model has two periods, two bank assets, a representative bank and a regulator. The representative bank minimizes, over a one-period horizon, the risk of a portfolio consisting of a high-risk asset and a low-risk asset. Risk minimization is subject to a constraint requiring that the portfolio return cannot fall below the required rate of return available in the rest of the economy, otherwise the bank fails to attract capital. A second constraint sets an upper limit on the high-risk asset weight imposed by the regulator to reduce the occurrence of a future crisis. Furthermore, the bank incurs a profit-reducing regulatory cost, but does not plan for the possibility of a future crisis. This myopic behavior can be justified either as a gamble that a crisis may affect other banks but not herself or that the regulator (backed by government) will come to the rescue of the bank if a crisis materializes. The regulator's objective is to stabilize the banking system and shares similar preferences of the representative bank with two important differences. The first is that it has a long planning horizon and maximizes the present value of the bank's expected income. The second is that the regulator, in thinking about the future, imbeds the expected loss due to a bank default into the income stream of the representative bank. This loss is the probability of a bank default times the impact of such a default on income (i.e., what is known as the loss given default), which in turn is a function of the investment in regulation and the quality of institutions. The critical implications for this paper emerge by comparing the case when regulation effectively constrains the weight on the risky asset to when it does not: the slope of the probability curve 
of bank default with respect to regulatory investment is negative in the first case and positive in the second. In other words, the probability curve is concave with respect to the level of regulation, the concavity stemming from the stringency of regulation.

The theoretical non-linearity is confirmed by the data. Using annual data from 1999 to 2011 drawn from 132 countries, we test the relationship between regulatory stringency and the probability of a crisis by estimating a Probit model of a non-linear specification. Our key inference is that the probability of a financial crisis fits an inverted U-shaped curve: it rises as regulation stringency moves from low to medium levels and falls from medium to high levels. The intriguing implication of this finding is that countries located at the intermediate level of regulatory stringency face more financial instability than countries that are either loosely regulated or severely regulated. We identify the latter groups as falling in two "liberalization traps." Another finding of note is that institutional quality interacts significantly with the regulatory environment; for a given level of regulatory investment, an improvement in institutional quality reduces the probability of a crisis. ${ }^{4}$ All of the results are robust to a battery of different econometric exercises.

The paper is organized as follows. Section II develops the theoretical model. The empirical equation and description of the data appear in Section III. Findings and robustness checks are discussed in Section IV. Conclusions are drawn in Section V. Appendices include details of the theoretical model and a full list of variables with their sources.

\section{THEORETICAL MODEL}

Our model has two periods, two assets, and two players. One player is a representative bank that minimizes the risk of a portfolio consisting of a high-risk asset and a low-risk asset. The

\footnotetext{
${ }^{4}$ The quality of institutions plays an important role in affecting the frequency and depth of crises. As DemirgucKunt and Detragiache (1998) note, post-liberalization banking crises are less frequent where the institutional environment is strong. Furthermore, banking competition, after deregulation, increases more in developed countries with robust institutions than in countries with weaker institutions (Delis, 2012).
} 
other player is the regulator who sets stricter rules on the bank's portfolio allocation so as to reduce bank risk-taking and mitigate the loss given default (LGD). The latter cannot be completely eliminated because it is affected by exogenous factors such as the quality of institutions. ${ }^{5}$ Regulation is costly and banks pay for it up front. Given that portfolio allocation is not observable, the regulator imposes minimum capital requirements, as in the Basel agreements. These capital requirements are equivalent to controlling asset allocation and are modelled here by placing an upper limit or a cap on the share of high-risk assets in the portfolio. The cap lowers the bank's profits and makes banking less attractive to investors. It also limits portfolio diversification and hence could expose the bank to higher idiosyncratic default risks. The regulator mitigates the bank's LGD. Three joint effects determine an inverted U-shaped relationship between regulatory stringency and the probability of bank default: the reduction in the share of high-risk assets in the bank's portfolio, its positive impact in terms of a lower LGD, and its negative impact on bank income.

The timeline of the model is as follows. Banks are homogenous and myopic, and minimize the one-period portfolio risk given the rate of return required by the capital markets. The regulator is benevolent, in the sense that it shares the banks' preferences, and forwardlooking, in the sense that his planning horizon is longer than the banks'. Current levels of regulation affects the future probability of bank default. We solve the model by first obtaining the one-period optimal share of high-risk assets in the portfolio of a myopic representative bank under asset allocation and market return constraints, and then determine the optimum level of regulation from a two-period utility function of the regulator.

\footnotetext{
${ }^{5}$ Another factor affecting the loss given default is the bank's priors regarding future crisis. Banks are risk neutral and update their priors in a Bayesian manner: if a crisis does not take place, banks expect a lower probability of firms' default and reduce non-performing loan provisions, whereas if a crisis takes place, surviving banks expect a higher probability of firms' default and increase non-performing loan provisions; see Aizenman (2009).
} 


\section{The bank problem}

A representative bank invests its income, net of the regulation cost, in a high-return high-risk asset $H$ and a low-return low-risk asset $L$ with a portfolio return $r_{p}$ and variance $\delta_{P}^{2}$ :

$$
\begin{aligned}
& r_{p}=(1-q)\left[1+r_{L}+\alpha\left(r_{H}-r_{L}\right)\right]-1 \\
& \delta_{P}^{2}=(1-q)^{2}\left[\alpha^{2}\left(\delta_{H}^{2}+\delta_{L}^{2}-2 \rho_{H L} \delta_{H} \delta_{L}\right)+2 \alpha\left(\rho_{H L} \delta_{H} \delta_{L}-\delta_{L}^{2}\right)+\delta_{L}^{2}\right],
\end{aligned}
$$

where $\alpha$ is the $H$ share in the bank's portfolio, $r_{H}>r_{L}$, and $\delta_{H}>\delta_{L}$. Furthermore, the correlation between the two assets, $\rho_{H L}$, must satisfy the condition $\rho_{H L} \leq \frac{\delta_{L}}{\delta_{H}}$ to ensure that $\delta_{\mathrm{P}}^{2}$ is a convex function of $\alpha .{ }^{6}$ We normalize current bank income to 1 and define with $q$ the investment in regulation decided by the regulator, whose cost is borne by banks: $0 \leq q \leq 1$, with $q=0$ corresponding to complete financial liberalization on $H$, and $q=1$ corresponding to $\alpha=0$, a "narrow" banking system, where banks hold only relatively safe assets. The regulator caps $\alpha$ through a continuous and double-differentiable function $G(q, \theta)$, where $\theta$ represents the lowest politically acceptable value of the cap in $H$ share. The constraint on the $H$ share asset is given by the following inequality:

$$
\alpha \leq G,
$$

where $0 \leq G \leq 1$, with $G_{q}^{\prime}<0$ and $G_{q}^{\prime \prime}<0$. An increasing negatively sloped $G$ captures the notion that regulatory complexity increases more than proportionally when the constraints interact with the model.

Capital markets are competitive and the bank can survive only if the after-tax $r_{p}$ is at least equal to the required rate of return:

$$
(1-q)\left[\alpha r_{H}+(1-\alpha) r_{L}\right] \geq \bar{r}
$$

where $\bar{r}$ denotes the exogenous required rate of return.

$$
{ }^{6} \frac{\partial \delta_{P}^{2}}{\partial \alpha}=\left[2 \alpha\left(\delta_{H}^{2}+\delta_{L}^{2}-2 \rho_{H L} \delta_{H} \delta_{L}\right)+2\left(\rho_{H L} \delta_{H} \delta_{L}-\delta_{L}^{2}\right)\right](1-q)^{2} \geq 0 \text { if } \rho_{H L} \leq \frac{\delta_{L}}{\delta_{H}} .
$$


Banks minimize their portfolio variance under the regulator-imposed asset share restriction and the market-imposed constraint of a required rate of return:

$$
\min _{q} \delta_{P}^{2} \quad \text { s.t. } a \leq G \text { and }(1-q)\left[\alpha r_{H}+(1-\alpha) r_{L}\right] \geq \bar{r}
$$

Three solutions of the problem are strictly relevant for this paper; see Appendix A for details. ${ }^{7}$ The first refers to the case when neither of the two constraints are binding. ${ }^{8}$ Banks are free to choose their share of high-risk asset $H$ :

$$
\hat{\alpha}=\frac{\delta_{L}^{2}-\rho_{H L} \delta_{H} \delta_{L}}{\delta_{H}^{2}+\delta_{L}^{2}-2 \rho_{H L} \delta_{H} \delta_{L}}
$$

The second refers to the case when only the market-imposed required rate of return constraint is binding:

$$
\widehat{\alpha}_{\gamma}=\frac{\bar{r}-r_{L}(1-q)}{\left(r_{H}-r_{L}\right)(1-q)} .
$$

The third refers to the case when only the regulator-imposed constraint on the $H$ asset share is binding:

$$
\hat{\alpha}_{\lambda}=G
$$

\section{The regulator problem}

The forward-looking regulator maximizes the representative bank's expected profits over a two-period horizon. ${ }^{9}$ Current bank income is known. Future income is not and the regulator takes its expected value, net of the impact of a probable crisis $P Q(G, \tau) .{ }^{10} P$ denotes the probability made at time $t$ that a crisis may occur at time $t+1$ and $Q(G, \tau)$ is LGD, the loss that would occur should a crisis erupt; $Q_{G}^{\prime}>0$. By raising $q$, the regulator lowers the cap $G$ on $\alpha$

\footnotetext{
7 The Lagrangian function is: $\mathcal{L}=(1-q)^{2}\left[-\alpha^{2}\left(\delta_{H}^{2}+\delta_{L}^{2}-2 \rho_{H L} \delta_{H} \delta_{L}\right)-2 \alpha\left(\rho_{H L} \delta_{H} \delta_{L}-\delta_{L}^{2}\right)-\delta_{L}^{2}\right]+\gamma\left\{(1-q)\left[r_{L}+\alpha\left(r_{H}-r_{L}\right)\right]-\bar{r}\right\}+\lambda[G-\alpha]$ where $\gamma$ and $\lambda$ are Lagrangian multipliers of the required market return and regulatory stringency constraint, respectively.

${ }^{8}$ This is possible with negative asset correlation.

${ }^{9}$ As frequently happens, the regulator is not subject to a budget constraint.

${ }^{10}$ The recursive nature of the problem and the fact that the current regulation affects the future probability of bank default reduce the regulator's problem to a two-period optimization.
} 
that, in turn, mitigates LGD, that is $0<Q \leq 1$. The second argument of $Q(),. \tau$, captures an exogenous level of the quality of institutions affecting the country's resilience to a crisis: the better are the institutions, the lower is LGD. The parameter $\tau$ is bound between zero and one, and prevents the possibility of $Q=0$.

The regulator faces the following two-period maximization problem:

$$
\max _{q} V(q)=\max _{q}\left\{(1-q)+\beta(1-q)\left[1+r_{L}+\alpha\left(r_{H}-r_{L}\right)\right](1-P Q)\right\}
$$

where $\beta$ is a discount factor. The benevolent regulator imbeds the solution of $\alpha$ obtained from the bank problem in his maximization problem; see equations (6)-(8). Again, we work out the details of the model in Appendix A and emphasize here the relevant cases.

Under a scenario of financial liberalization, i.e., $\alpha=\hat{\alpha}$ (eq. (6)), we obtain the probability of a crisis from the first-order condition, $\frac{\partial V(q)}{\partial q}=0$ :

$$
P=\frac{1+k}{k} \cdot \frac{1}{\left[Q-(1-q) Q_{G}^{\prime} G_{q}^{\prime}\right]}
$$

where $k=\beta\left[1+r_{L}+\frac{\delta_{L}^{2}-\rho_{H L} \delta_{H} \delta_{L}}{\delta_{H}^{2}+\alpha \delta_{L}^{2}-2 \rho_{H L} \delta_{H} \delta_{L}}\left(r_{H}-r_{L}\right)\right]>0$. Its derivative with respect to $q$ is:

$$
\frac{\delta P}{\delta q}=-\frac{1+k}{k} \cdot \frac{2 Q_{G}^{\prime} G_{q}^{\prime}-(1-q)\left[Q_{G}^{\prime \prime} G_{q}^{\prime 2}+Q_{G}^{\prime} G_{q}^{\prime \prime}\right]}{\left[Q-(1-q) Q_{G}^{\prime} G_{q}^{\prime}\right]^{2}} \geq 0
$$

if $2 Q_{G}^{\prime} G_{q}^{\prime} \geq(1-q)\left[Q_{G}^{\prime \prime} G_{q}^{\prime 2}+Q_{G}^{\prime} G_{q}^{\prime \prime}\right]$. In words, in the absence of binding constraints from the regulator and market forces, the higher the investment in regulation $q$, the higher is the probability of a crisis $P$. Countries prefer to continue the process of financial liberalization.

Under a binding market return scenario, $\alpha=\widehat{\alpha}_{\gamma}$ (eq. (7)), the probability of a crisis is:

$$
P=-\frac{1}{\beta(1+\bar{r}) Q_{G}^{\prime} G_{q}^{\prime}},
$$

which is bounded between zero and one if $-\frac{1}{\beta(1+\bar{r})}<Q_{G}^{\prime} G_{q}^{\prime}<0$. It can be shown that (12) is larger than (10), a result that is consistent with the bank taking more risk to meet the stringent 
required rate of return and hence reaping larger benefits from the regulator's protection. The derivative of $P$ with respect to $q$ is:

$$
\frac{\delta P}{\delta q}=-\frac{\beta\left(\bar{r}-r_{L}\right)\left[Q_{G}^{\prime \prime} G_{q}^{\prime 2}+Q_{G}^{\prime} G_{q}^{\prime \prime}\right]}{\left[\beta\left(\bar{r}-r_{L}\right) Q_{G}^{\prime} G_{q}^{\prime}\right]^{2}}>0
$$

so long as $Q_{G}^{\prime \prime}<0$. As in the financial liberalization scenario, a rise in regulation raises the probability of a crisis. Therefore, countries will continue to liberalize. The only difference between the two scenarios is that the market-imposed constraint raises the $H$ share relative to the financial liberalization case.

Under stringent regulation, $\alpha=\hat{\alpha}_{\lambda}=G$ (eq. (8)), the probability of a crisis is:

$$
P=\frac{1+A+B\left(G-(1-q) G_{q}^{\prime}\right)}{A\left(Q-(1-q) Q_{G}^{\prime} G_{q}^{\prime}\right)+B\left[Q G-(1-q)\left(Q_{G}^{\prime} G_{q}^{\prime} G+Q G_{q}^{\prime}\right)\right]}=\frac{N(q)}{D(q)}>0
$$

where $A=\beta\left(1+r_{L}\right)$ and $B=\beta\left(r_{H}-r_{L}\right)$. Its derivative with respect to $q$ is:

$$
\frac{\partial P}{\partial q}=\frac{N^{\prime}(q) D(q)-N(q) D^{\prime}(q)}{D(q)^{2}} \leq 0,
$$

provided $N^{\prime}(q) D(q) \leq N(q) D^{\prime}(q)$. A rise in regulatory investment, when regulation bites, reduces the probability of a crisis.

In sum, a higher $q$ raises $P$ under a regime of financial liberalization and under a stringent market-imposed constraint, and lowers $P$ under a stringent regulatory constraint. For a better understanding of these critical relationships, we carry out simple simulations to show that, not only the required conditions for the signs of $\frac{\partial P}{\partial q}$ are feasible, but they hold also for a wide range of values of the underlying variables. To this end, we rely on Beta functions to parameterize $0 \leq q \leq 1,0 \leq G \leq 1$ and $0 \leq Q \leq 1$. More specifically, we use the complement to one of an incomplete Beta function to obtain non-negative functions with nonpositive monotonic first derivatives. To accommodate the politically acceptable level $\theta$ and the quality of institutions, $\tau$, incomplete Beta functions are multiplied by inefficiency factors, such as: 


$$
\begin{aligned}
& G=1-\theta I_{q}\left(a_{G}, b_{G}\right) \\
& Q=1-\tau I_{q}\left(a_{Q}, b_{Q}\right)
\end{aligned}
$$

where $I_{q}(a, b)$ denotes the incomplete Beta function of $q$ defined as:

$$
I_{q}(a, b)=\frac{B_{q}(a, b)}{B(y, z)}=\frac{1}{B(y, z)} \int_{0}^{q} x^{a-1}(1-x)^{b-1} d x
$$

with $a>0, b>0$ and $B(y, z)=\int_{y}^{z} x^{a-1}(1-x)^{b-1} d x$. Note that, while $0<\theta \leq 1$, in the real world, $\theta$ is very close to 1 because the regulator can impose a very stringent regulation. For simplicity, we assume $\theta=1 .^{11}$ Similarly, while $0<\tau \leq 1$, we restrict its value to an average quality of institutions, i.e., $\tau=0.5$.

In sympathy with the optimization problem, we set $a_{G}=3$ and $b_{G}=1$ for $G$ and $a_{Q}=$ 1 and $b_{Q}=3$ for $Q$. The symmetry of the parameter values is imposed for convenience, whereas $b_{G}=1$ and $a_{Q}=1$ to avoid sign reversals in the second derivatives. ${ }^{12}$ Also, we use $\frac{\partial Q}{\partial q}$ as a short cut of $\frac{\partial Q}{\partial G} \cdot \frac{\partial G}{\partial q}$. In brief, $G$ and $Q$ are defined as follows:

$$
\begin{array}{ll}
G=1-\frac{\theta}{B(y, z)} \int_{0}^{q} x^{a_{G}-1}(1-x)^{b_{G}-1} d x & \text { with } \theta=1, a_{G}=3, \text { and } b_{G}=1 \\
Q=1-\frac{\tau}{B(y, z)} \int_{0}^{q} x^{a_{Q}-1}(1-x)^{b_{Q}-1} d x & \text { with } \tau=0.5, a_{Q}=1, \text { and } b_{Q}=3 .
\end{array}
$$

Figure 1 shows the profile of $\frac{\partial P}{\partial q}$ under the three scenarios. In the first two scenarios (black solid and blue dashed curves), $\frac{\partial P}{\partial q}$ is positive; in the third scenario (red solid curve), with a binding regulatory constraint, it is negative provided certain general conditions are met. Therefore, simulations are particularly informative about the third scenario. To ensure a certain degree of robustness, we checked the sensitivity of our results with respect to a broad range of parameter

\footnotetext{
${ }^{11}$ Results are virtually the same with lower values of $\theta$.

${ }^{12}$ We get similar results with $a_{G}=b_{Q}=6$ and $a_{G}=b_{Q}=9$.
} 
values. ${ }^{13}$ In all cases, a higher $q$, when regulation is binding, lowers the risk of a crisis. Lastly, by combining either scenario one or scenario two with scenario three, we obtain the fundamental concavity relationship between investment in regulation and crisis probability, a primary objective of the paper. In addition, simulations show that there is a more intense reaction to regulation at lower values of $\tau$, thus revealing the importance of good institutions (graph not reported for brevity). We will see in the next section that this concavity is confirmed by the data.

[Insert here Figure 1]

\section{EMPIRICAL MODEL AND DATA}

The main implication of our theoretical model is that regulation has a non-linear impact on the probability of a crisis, a finding that reconciles the mixed results found in the empirical literature. To confirm our hypothesis, we develop in this section an empirical framework that draws on Hutchison and McDill (1999) and Barth et al. (2001), and assumes a causal nexus from regulation to banking crises. The test uses a Probit regression to infer how regulation and quality of institutions affect the probability of a banking crisis, given a set of macroeconomic and cultural control variables.

The empirical framework and hypotheses testing

We propose three different hypotheses: the traditional linear hypothesis, HYP1, which tests that the probability of a banking crisis increases as regulation increases; the non-linear hypothesis, HYP2, which tests an inverted U-shaped relationship between regulation and banking crisis; the interacting effects hypothesis, HYP3, which tests that the regulation-crisis non-linear relationship is also influenced by the quality of institutions. Both HYP2 and HYP3 are implications of our theoretical model.

\footnotetext{
${ }^{13}$ Given $a_{Q}, b_{G}=1$, the simulations were run for values ranging $3 \leq a_{G}, b_{Q} \leq 9,0.2 \leq \theta \leq 1,0.2 \leq \tau \leq 0.8$, and $0.6 \leq \beta \leq 0.8$.
} 
The specification of the linear hypothesis $(H Y P 1)$ is:

$$
\operatorname{CRISIS}_{i t}=f\left(\alpha+\beta F F I_{i t}+\gamma \operatorname{INST}_{i t}+\partial C T R L_{i t}+\varepsilon_{i t}\right),
$$

where $f($.$) is a Probit transformation function and \varepsilon$ is a well-behaved idiosyncratic error term. The dependent variable is a dummy variable that is equal to one during a banking crisis and zero otherwise; FFI stands for the Financial Freedom Index, our inverted proxy of the level of regulation; INST is a measure of country-specific institutional quality; and CTRL is a set of one-year lagged macroeconomic variables, such as the consumer price index inflation rate (INFL), the current account balance as a percentage of GDP $(C A B)$, and per capita GDP in current US dollars $(G D P p c){ }^{14}$

$G D P p c$ affects negatively financial stability for two reasons. The first is that poor countries do not save enough to develop financial markets and, hence, are subject to fewer and/or less intense crises. ${ }^{15}$ This expectation is in line with the evidence from the 2008-2009 financial crisis that affected directly the US and the EU, indirectly Asian and Latin American countries, and only marginally the financially less developed regions of the world, such as Africa (Fratianni and Marchionne, 2013). The second reason is technical. As per-capita income falls during a crisis and increases afterwards, the one-year lagged GDPpc captures this negative correlation.

The expected impact of INFL and CAB on CRISIS is positive. A high inflation rate indicates a mismanagement of macroeconomic policy (Demirgüç-Kunt and Detragiache 1998). A large current account deficit is symptomatic of a deteriorating competitiveness, which in turn raises the probability of a sovereign debt crisis; see Beker and Moro (2016) with reference to the EU and Section IV below.

\footnotetext{
${ }^{14}$ GDPps is defined as GDP per capita in current US dollar divided by 10,000 .

${ }^{15}$ For example, a subsistence economy is not affected by financial crisis
} 
In some specifications, we introduce two other variables. The first, TOP5, measures bank concentration at the country level with the share of asset value held by the five largest commercial banks in the country. According to the traditional charter value paradigm, banking concentration improves financial stability because it guarantees a rent to incumbent banks, increases their charter value, and, hence, reduces incentives to risk-taking (Keeley 1990). We expect a negative coefficient for TOP5. The second variable, $B A S$, measures bank size as total assets held by deposit money banks as a share of GDP. We expect the coefficient of $B A S$ to be negative because of the implicit government subsidy and guarantees that oversized banking sectors receive (Fratianni and Marchionne, 2016). Finally, institutional quality has a positive impact on financial stability because a more transparent governance improves the monitoring of the financial sector and a cheaper crisis resolution. This implies $\gamma<0$.

The Financial Freedom Index, FFI, is an inverse proxy of regulatory stringency and measures financial sector independence from government control and interference. The proposition is that a very stringent regulation limits diversification opportunities and leads to excessive risk, that is $\beta<0$.

The conflicting empirical results we have reviewed could stem from a failure to capture the non-linear impact of regulation on financial stability. The theoretical model of Section II addresses specifically this issue. The specification of the non-linear hypothesis (HYP2) is:

$$
\operatorname{CRISIS}_{i t}=f\left(\alpha+\beta_{1} F F I_{i t}+\beta_{2} F F I^{2}{ }_{i t}+\gamma I N S T_{i t}+\partial C T R L_{i t}+\varepsilon_{i t}\right),
$$

where $\beta_{1}>0$ and $\beta_{2}<0$. This pattern creates a pendulum in regulation, which will be discussed below. After a crisis and regulation tightening, financial liberalization takes a step backward with inefficiency consequences. This phenomenon is particularly evident in countries with under-developed financial markets where the benefits from liberalization are limited and unstable (e.g., Argentina, Greece). 
Ambiguous findings could be due also to differences in institutional quality. Liberalization policies are beneficial when they are implemented in economies with seasoned and transparent institutions; in countries plagued by corruption and bad governance, instead, liberalization may generate no payoff or be outright destabilizing. The specification of the third hypotheses, HYP3 is:

$\operatorname{CRISIS}_{i t}=f\left(\alpha+\beta_{1} F F I_{i t}+\beta_{2} F F I^{2}{ }_{i t}+\gamma I N S T_{i t}+\partial C T R L_{i t}+\Psi_{1} F F I * I N S T+\Psi_{2} F F I^{2} * I N S T+\varepsilon_{i t}\right)$

The change with respect with HYP2 is that we have added here a linear and a quadratic interactive term between INST and FFI. The expectation is that, with weak institutions, the inverted U-shaped regulation-crisis curve is steeper and achieves its maximum at a lower value of FFI: that is, $\psi_{1}<\beta_{1}$ and $\beta_{2}>\psi_{2}$ (given $\beta_{1}<0$ and $\beta_{2}>0$ ).

\section{$\underline{\text { Data and descriptive statistics }}$}

Our data consist of an unbalanced panel of 132 countries covering the period 1999 to 2011 and including 2,832 annual observations. We have collected information from different sources. Data on banking crises come from Laeven and Valencia (2013), regarded as the most accurate dataset on the subject (Chaudron and de Haan 2014). ${ }^{16}$ We use this data set to create two crisis variables: CRISIS, our main dependent variable, is a dummy equal to one during a banking crisis, and zero otherwise; ALL_CRISIS is a dummy that takes value of one during a banking crisis, or a sovereign debt crisis or twin crises, and zero otherwise. We use primarily CRISIS, while $A L L \_C R I S I S$ is employed in robustness exercises to take into account for a possible impact of a sovereign debt crisis on a banking crisis (Beker and Moro, 2016). ${ }^{17}$ In our sample, we identify 143 banking crisis years, of which 43 occurring before 2008, and 23 sovereign debt crisis years, of which 18 before 2008 .

\footnotetext{
${ }^{16}$ Other sources of banking crises data are Caprio et al. (2005) and Reinhart and Rogoff (2008).

${ }^{17}$ During the European sovereign debt crisis emerged a perverse sovereign-banking feedback loop stemming from the double interconnection between the sovereign and the banking sector: domestic banks held a considerable part of the national sovereign debt and the fiscal cost of government rescuing banks was huge. Consequently, a financial turmoil that puts in doubt sovereign solvency spills over also onto the balance sheets of creditor banks (Fratianni and Marchionne 2016).
} 
The financial freedom index, FFI, measures the degree of the country's independence from government control and interference. ${ }^{18}$ It ranges from 0 to 100: the higher the score, the freer the financial sector. Figure 2 shows that the bulk of crisis years in the sample occurs with a value of FFI equal to or higher than 50. From the World Development Indicators database of the World Bank (2016) we have drawn the annual percentage change of the consumer price index $(I N F)$, the current account balance as a percentage of GDP $(C A B)$, and GDP per capita in current US dollars $(G D P p c)$, the ratio of assets held by the five largest banks to total commercial banking assets (TOP5), and total assets held by deposit money banks as a share of GDP $(B A S)$. From the Worldwide Governance Indicators database of the World Bank (2015) we have taken six measures of institutional quality: government effectiveness, regulatory quality, rule of law, voice and accountability, corruption control, and political stability. We control for the specificity of Europe and the Great Financial Crisis with three dummies. $E U$ and $E U R O$ take value of one if the country is part of the EU or the Eurozone, respectively, thus also reflecting the year of the formal affiliation to the European Union and European Monetary Union. PERIOD is equal to one for observations starting in 2008. Finally, country-specific cultural variables come from La Porta et al.'s (1999) database: the country's legal origin dummy (ENGLISH) takes value one if the country adopts a common law system; MUSLIM is the percentage of Muslims in total population and captures cultural distance. ${ }^{19}$ Appendix B gives a complete description of the variables and their sources.

\footnotetext{
${ }^{18}$ FFI covers five broad areas: (i) the extent of government regulation of financial services, (ii) the degree of state intervention in banks and other financial firms through direct and indirect ownership, (iii) the extent of financial and capital market development, (iv) government influence on the allocation of credit, and (v) openness to foreign competition; for more details, see http://heritage.org/index/book/methodology.

${ }^{19}$ We group legal frameworks other than the common law system to reduce the number of dummy variables, increase the probability of convergence in our regressions, and improve the efficiency of the estimates. We use MUSLIM as a proxy of cultural distance for three reasons. The first is that the Islamic culture is strongly based on traditions. It implies that Islam is resilient to the process of globalization affecting other cultures and it is a better candidate to capture Within country heterogeneity. The second is that the cultural distance between Islam and other religions is higher than the differences among other religions. The third is that using the percentage of citizens in place of a dummy variable is a more precise measure of the cultural distance within a country.
} 
[Insert Figure 2 here]

Descriptive statistics are reported in Table $1 .{ }^{20}$ Banking crisis episodes represent $7 \%$ of the observations and are only $0.7 \%$ less than all crises, confirming a strict correlation between banking and sovereign debt crises. FFI ranges from 0 to 90 with an average of around 50 and a standard deviation of 20 . The relatively low coefficient of variation $(0.402)$ reflects the fact that the index changes slowly over time. The variables measuring institutional quality range approximately from -2.5 to 2.5 , with higher values corresponding to better governance. We normalize them between 0 and 1 so as to remove any cross-variable discrepancy. The six variables are highly correlated: all pairwise correlations are highly positive and significant at the $1 \%$ level. Given that the lowest correlation is 0.65 , we average the six institutional measures in one synthetic Institutional Quality Index (IQI).

\section{[Insert here Table 1]}

Table 2 tests the difference of the means (Panel A) and medians (Panel B) of each variable between EU and non-EU countries in the pre-crisis period (column 1 vs column 2), crisis period (column 3 vs column 4), and between pre-crisis and crisis periods for EU countries (column 5). EU countries have better institutions and a higher FFI than non-EU countries in both periods. Furthermore, the 2008-2009 financial crisis produced less of a structural break in the EU than elsewhere in the world. In fact, FFI is not statistically different across periods for the EU countries, but it is for non-EU countries that experience an increase in regulation (statistical significance not reported). The average banking sector-to-GDP ratio $(B A S)$ increased after 2008 in both sub-samples for two reasons. The first is that the GDP decline was larger than the banking sector collapse. The second is that banks and government struck up a sort of implicit mutual protection pact, whereby banks raised their portfolio of government

\footnotetext{
${ }^{20}$ We removed severe outliers (e.g. 24,441\% inflation rate in Zimbabwe in 2007).
} 
securities against the no-default protection accorded to them by the government (Fratianni and Marchionne, 2016).

[Insert here Table 2]

\section{EMPIRICAL RESULTS}

Two econometric issues arise with the use of a binary dependent variable in panel data. The first is the incidental parameter problem, which biases the fixed effects estimator under a limited time dimension. ${ }^{21}$ Furthermore, as fixed effects omit countries unaffected by a crisis, the number of observations in the estimates falls. A random effects model does not suffer from these shortcomings, but the assumption that country effects are uncorrelated with the independent variables is incompatible with our dataset. An alternative strategy is to use the Correlated Random Effects Model (CREM) (Wooldridge, 2010). The second issue is that the probability of a crisis is persistent and hence requires a lagged dependent variable as a regressor. A Dynamic Random Effects (DREM) Model controls for the serial correlation and the initial value problem (Wooldridge, 2005). So, our estimation strategy is to use a pooled Probit as a benchmark model and CREM and DREM as robustness tests. Potential simultaneity and reverse causality biases are controlled using one-year lagged independent variables, except for institutional variables that change slowly; see descriptive statistics. ${ }^{22}$

\section{Main findings}

\footnotetext{
${ }^{21}$ As the ratio of the number of observations to the number of parameters increases, the parameter estimates will converge to their true values as standard errors become arbitrarily small. With fixed effects, this does not happen because the number of parameters grows with the number of observations. Monte Carlo exercises show that the resulting estimator remains biased even with 20 periods (Greene, 2004).

${ }^{22}$ Banking regulation does not change substantially year by year because it is difficult to obtain a large political consensus, in particular during or shortly after a crisis. For example, see the tormented iter in the approval and implementation of the Basel III agreement.
} 
Different specifications of the benchmark model are presented in Table 3. The base specification includes L.GDPpc, L.TOP5, IQI, PERIOD capturing a structural break in 2008, and $E U$ (column 1). ${ }^{23}$ The linear HYPI is rejected because L.FFI is statistically insignificant (column 2). When we add the squared term, a significant inverted U-shaped relationship between regulation and the probability of a banking crisis emerges (column 3); it corroborates HYP2. We control for potential omitted macroeconomic variables with L.CAB and L.INF (column 4). Given the simultaneous increase in the McFadden pseudo $\mathrm{R}^{2}$ and a decrease in both AIC and BIC, we elect columns 5 and 6 as the benchmark specifications of $H Y P 1$ and $H Y P 2$, respectively. The negative $I Q I$ coefficient suggests that better institutions reduce the probability of a banking crisis. In all specifications, this probability increases with L.INF and L.GDPpc: they capture, respectively, the risk of investment at the country level and the negative serial correlation between a banking crisis and the previous year's income. The beneficial effect of banking concentration, L.TOP5, confirms the charter value paradigm. ${ }^{24}$ PERIOD is highly significant and positive, whereas interestingly EU members have a greater probability of being affected by crises. In the last two columns, we check the sensitivity of our findings to the liberalization index by replacing $F F I$ with two popular measures of financial liberalization, one produced by Abiad et al. (2010) and the other by Barth et al. (2013). ${ }^{25}$ The three indexes have different coverage and the unavailability of data in other variables limits us in going backwards in the sample (e.g. IQI, TOP5). ${ }^{26}$ Hence, samples are smaller when we

\footnotetext{
${ }^{23}$ Prefix $L$ denotes a lagged variable.

${ }^{24}$ According to this theory, a less competitive sector increases bank charter values that, in turn, leads banks to limit risk exposure to avoid failure and enjoy high profits (OECD, 2011; Marchionne and Zazzaro (2013).

${ }^{25}$ Abiad et al. (2010) deploy an aggregated index of financial liberalization ranging from 0 to 21 , where the higher values denote a more liberal financial sector. We re-scale this index between 0 and 100, like FFI. We then use Barth et al.'s (2013) broad dataset on banking regulation to construct a comprehensive measure of financial liberalization by aggregating four indexes (Capital Regulatory Index, Overall Financial Conglomerates Restrictiveness, Entry into Banking Requirements and Overall Restrictions on Banking Activities) and re-scaling it between 0 and 100, where the higher the score denotes a more liberal financial system.

${ }^{26}$ The Heritage Foundation FFI covers 221 countries starting in 1995; Abiad et al.'s (2010) financial liberalization index has data for 91 countries until 2005, and Barth et al.'s (2013) coverage is for 180 countries but only from 1999 to 2011.
} 
rerun HYP2 using the rescaled FFIs obtained from these alternative datasets instead of our original dataset. Results are stronger and fully corroborate our non-linear hypothesis.

[Insert here Table 3 and Figure 3]

Using the adjusted HYP2 results of column 6, we plot the impact of L.FFI on the probability of a crisis before and after the Great Financial Crisis $(P E R I O D=0$ and $P E R I O D=1)$, for both non-EU and EU countries $(E U=0$ and $E U=1)$; see Figure 3, middle line. ${ }^{27}$ The figure can also be read, on the $\mathrm{x}$-axis, from right to left in term of regulation, given that the latter is 100-FFI: it confirms the concavity in the crisis-regulation space that emerges from our theoretical model. Also, EU countries have been more prone to crises than non-EU countries (right vs. left panels) and the failure of Lehman Brothers marked a dramatic increase in the probability of a crisis in both regions (top vs bottom panels). The probability of a crisis peaks at $F F I \approx 70$. For these medium countries, which are distant from the extremes of loose regulation and oppressive regulation, moderation does not seem to pay because the probability of a crisis falls on either side of the peak. It follows that moving towards the extreme is a superior strategy than staying in the middle. ${ }^{28}$ This is particularly relevant for EU countries that score approximately 69 in the FFI: they are very close to the maximum probability of a banking crisis ( $40 \%$ on average); see Table 2.

The inference we draw from our results is that two liberalization traps may be operating. For the first, start from the west side of the peak point in Figure 3. A liberalization process raises efficiency but increases the probability of a crisis. When a crisis occurs, the banking system is up-regulated with negative consequences on efficiency and profitability. Tranquil

\footnotetext{
${ }^{27}$ When dealing with non-linear models, a graphical analysis proves to be useful for the interpretation of the outcomes. To this end, the adjusted predictions are calculated by keeping all the independent variables to their mean except that $L . F F I$ and the two dummies, while observing on the horizontal axis different values of the Financial Freedom Index. The dummies split our sample in four sub-samples and allow us to observe the probability of a crisis to occur for each different level of $F F I$ in each sub-sample.

${ }^{28}$ Interestingly, the probability of a crisis is the same at $F F I=100$ and $F F I=30$, even if financial markets are more efficient at higher $F F I$ values; see http://www.heritage.org/index/financial-freedom for details on $F F I$ values.
} 
periods restore a mood for complacency; restrictions are again loosened, bringing about another increase in efficiency but with a positive probability of a crisis. Basically, as it climbs the crisis hill, the banking system, like Sysyphus, rolls back to the valley. This up-and-down pattern characterizes the regulatory pendulum along a liberalization path; the pendulum being more pronounced for countries with poorer institutions, such as Latin America countries in the 1970s and the 1990s. If a crisis does not occur, the banking system continues to liberalize, may go over the peak point, and settle on the east side of the hill, where the probability of a crisis declines, while remaining positive. When a crisis occurs, the regulator up-regulates, blaming the turmoil on excessive liberalization. But, up-regulation is resisted because it raises the probability of a crisis: the banking system prefers the return to a lower regulatory regime, albeit unstable, to a safer position on the west side of the hill. This is the pattern of the second liberalization trap, a pendulum in regulation along the path of a fuller liberalization. The United States in 2017 would be an example of a country that would like to down-regulate after having introduced the strict regime of the Dodd-Frank Act. A sharp swing from the east side to the west side of the peak would occur in the case of a severe crisis, like that of the 1930s: a massive up-regulation would be necessary to stop the turmoil, with adverse consequences on efficiency and profitability.

Moving to HYP3, note that we cannot directly include interaction terms in Probit estimates because the marginal effect of a change of the interacting variables is not equal to the marginal effect of just changing the interaction term. ${ }^{29}$ We follow Greene (2010) in applying adjusted predictions to the interaction of $I Q I$ with $F F I$; see Figure $3 .{ }^{30}$ Adjusted predictions keep all independent variables at their means, except for FFI and IQI that instead increase

\footnotetext{
29 "More surprisingly, the sign may be different for different observations. The statistical significance cannot be determined from the z-statistic reported in the regression output" (Ai and Norton, 2003, p.154).

${ }^{30}$ Greene (2010, p.295) points out "Partial effects are neither coefficients nor elements of the specification of the model. They are implications of the specified and estimated model.[...] We find that graphical presentations are a very informative adjunct to numerical statistical results."
} 
gradually from low to high values, and the dummy variables $E U$ and PERIOD. The second message of Figure 3 is that institutional quality alters the position of the crisis probability curve against the FFI index: the lower the quality of institutions, the heavier and darker the curves. Countries with poorer institutions face a greater risk of a banking crisis, particularly in the EU. For example, before 2008 an EU country with $I Q I=1$ faces a tiny probability of financial distress, but a sizable one when $I Q I=0$ (the maximum probability rising to $40 \%$ at $F F I=70$ ). A similar pattern holds for non-EU countries. Once again, the location of the medium-level countries in the FFI index suggests that these countries may not rejoice about their prospects of a future crisis.

EU members suffer from a regulatory coordination problem. A stricter regulation reduces the probability of a crisis when $F F I<70$; for example, in Greece and Romania. Given the relationship between the liberalization trap and IQI, finance-developing countries should be prudent in liberalizing the financial sector. ${ }^{31}$ Countries with FFI $>70$, such as Denmark and Finland, instead, minimize the probability of a crisis at $F F I=100$, and can afford to further liberalize their financial sector. Furthermore, there is a trade-off between institutional quality and regulation. Countries with poor institutions must accept a more regulated financial sector to contain financial instability, whereas countries with good institutions can afford a more liberal financial environment. Brexit is a case in point of contrasting views on banking regulation between the UK and the EU. Due to good institutions, the UK minimizes the probability of a crisis with an extremely liberal financial environment, as one can infer from a score of $F F I=86$; conversely, EU continental countries with lower institutional quality minimize crisis probability with tighter rules, as one can infer from an average score of $F F I<70$. Under heterogeneous preferences for policy reforms, a common regulation is inefficient

\footnotetext{
31 The pattern is consistent also with the experience of Latin American countries: the two waves of financial liberalization in the 1970s and 1990s were rapidly followed by deep financial disturbances (Mishkin, 1999).
} 
because it pushes some countries away from their optimal combination of institutional quality and regulatory stringency. As a result, a common regulatory setting will be difficult to achieve and/or is unstable. ${ }^{32}$

\section{$\underline{\text { Additional findings }}$}

We now take up additional findings of our analysis. For this purpose we introduce the following variables: $L . B A S$ is a measure of the size of the domestic banking sector; ENGLISH is a dummy capturing the legal origin of the countries (i.e., British-style common law systems); MUSLIM, the percentage of Muslims in the total population, is a proxy for Islamic commercial jurisprudence (including Islamic banking); and $E U R O$ is a dummy for the Eurozone countries that substitutes for the dummy $E U$. Legal origin and religious composition are variables widely used in the literature as determinants of financial development and as proxies of cultural affinity (La Porta et al., 1999; Beck et al., 2003; Lee and Lu , 2015).

\section{[Insert here Table 4]}

Results are presented in Table 4. Column 1 reports the estimate of the benchmark model (column 5 of Table 3 ). In column 2, we add L.BAS to test whether the size of the domestic banking sector matters and ENGLISH and MUSLIM to control for potential omitted cultural variables. Columns 3 and 4 report, respectively, the estimates of the benchmark and expanded model using EURO in place of EU. In column 5, we control for potential cross-country contagion effects by adding CONTAGION, a dummy that is equal to 1 when another country in the same region is affected by a crisis. The definition of the regions is provided by the World Bank. ${ }^{33}$ Since crises last several years, we also add TREND, a variable indicating the year number in the current crisis episode. The intent is to capture the impact of crisis persistence on

\footnotetext{
32 The internal contrasts in creating the European Banking Authority in 2011 and the protracted process in completing the European Banking Union are examples of a precarious bargain (De Rynck, 2015).

${ }^{33}$ Every geo-economic country classification is questionable but the World Bank regions have the advantage to be consistent over time. The World Bank identifies seven regions in the world: East Asia and Pacific, Europe and Central Asia, Latin America and the Caribbean, Middle East and North Africa, North America, South Asia, and Sub-Saharan Africa.
} 
next year's crisis probability; see column 6 . In column 7 , we control for both cross-country contagion and crisis persistence. Finally, in column 8 we replace CRISIS with ALL_CRISIS to verify the stability of results to the definition of crisis. All new variables are statistically highly significant.

The positive sign of L.BAS (column 2 and 4) suggests that, ceteris paribus, banking crises are more likely to occur in countries with larger banking sectors. An oversized sector may trigger an implicit government subsidy/protection that encourages the risk appetite of banks. L.FFI and L.FFI2 coefficients are stable and significant, confirming the inverted Ushaped impact of regulation on the probability of a crisis. Countries with a common law system and/or a substantial Muslim population are financially more stable than others (column 2 and 4). The impact of $E U R O$ is similar to that of $E U$, but less intense (compare column 1-2 with 34 respectively). Overall, institutional quality (IQI) improves financial stability. The only two exceptions are when we replace $E U$ with $E U R O$ and when we add CONTAGION: IQI is not significant in column 3 and marginally significant in column 5, but it raises the probability of a crisis as expected in column 4 and 7. All specifications, including the specifications with CONTAGION and TREND in column 5-7 and that of ALL_CRISIS in column 8, are consistent with the main findings of the benchmark model.

[Insert here Figure 4]

Figure 4 reports the same graphs of Figure 3 using $E U R O$ in place of $E U$. There are few differences. Moving from EU to Eurozone countries, the pre-2008 probability of a crisis is a half for low-IQI countries and is double for good institutional quality members. Graphically, the distance between the solid and the dotted line in the top right quadrant of Figure 4 is smaller than in the corresponding quadrant of Figure 3. This is due to the selection effect created by the Eurozone. During the crisis, Euro worked as a destabilizer at the expense of countries with good institutions. After 2008, the probability of a crisis in the Eurozone (right quadrants in 
Figure 4) increased proportionally more than in non-Euro countries (left quadrants in Figure 4) and EU countries (right quadrants in Figure 3). Within the Eurozone (right quadrants in Figure 4), the probability of a crisis increased by 3 times for high-IQI countries (dotted line) against 2.5 times for low-IQI ones (solid line). A more pronounced inverted U-shaped FFI pattern, especially for countries with good institutions, does not guarantee a stable financial system in the Eurozone.

The FFI mean for Eurozone members is around 68, a value very close to the maximum for each $I Q I$-level crisis probability curve. In this situation, not only a single response cannot fit all Eurozone countries, but also improvements in institutional quality will not be effective because high-IQI countries continue to face a considerable crisis probability (around 20\%). Hence, structural shortcomings of the Eurozone appear more severe than in the EU, regardless of banking regulation and institutional quality. Although Eurozone countries seem more coordinated than EU ones, remedies to stabilize the area must be conceived possibly looking beyond just a new financial regulatory framework.

\section{$\underline{\text { Robustness tests }}$}

We carry out four robustness exercises. The first is to apply a correlated random effects model $(C R E M)$ to permit a correlation between unobserved heterogeneity and observed covariates in a random effects model (Wooldridge, 2010). The implementation consists of adding a withincountry Mundlak correction done with a cross-section mean of all covariates (Table 5, columns 1 and 2). The second is to apply a dynamic random effects model (DREM henceforth) (Wooldridge 2005) to a specification that includes the lagged dependent variable intended to capture the persistence of crises. The implementation consists of adding a time-average Mundlak correction done with a temporal mean of all covariates and an initial year value of the dependent variable, CRISIS_tO (Table 5, column 3 and 4). The third is to combine both methods in a double correction model (DCOR henceforth) (Table 5, column 5 and 6). The joint F-tests 
show that correction terms are individually and jointly statistically very significant. The inverted U-shaped FFI pattern is always confirmed. The IQI impact is negative. The statistically significant positive coefficient of L.CRISIS does not alter results. Overall, previous findings are corroborated. ${ }^{34}$

\section{[Insert here Table 5]}

The fourth and final exercise verifies whether variables' persistence may drive our findings. For this purpose, we divide the sample in three-year sub-periods, collapse sub-periods data in four waves, and regress the dependent variable on the averages of the covariates of the previous three-year sub-period; i.e. the probability of a crisis in 2003, 2006, 2009, and 2012 on covariate averages for periods 2000-2002, 2003-2005, 2006-2008 and 2009-2011, respectively. The outcomes appear in Tables 6 and 7. The estimates in these two tables are in line with the estimates in Tables 3 and 4, thus confirming the validity of our earlier findings. It suggests that our results are robust to a slow reaction of the banking system to the introduction of regulation; e.g. a long implementation period or a slow adjustment in bank risk-taking.

[Insert here Tables 6 and 7]

\section{CONCLUSIONS}

Regulation can either reduce the probability of a banking crisis or increase it, depending on factors such as the stringency of regulation, the type of regulation, and the quality of institutions present in a country. Empirical findings in the literature, in fact, tend to be ambiguous on the link between regulation and probability of a banking crisis. In the light that positive and negative effects can emerge, we start with a theoretical model that produces both outcomes and arrives at the implication that the probability of a crisis is best described by a concave curve with respect to an investment in regulation. The theoretical non-linearity is confirmed by data.

\footnotetext{
${ }^{34} \mathrm{We}$ replicate the models presented in the first two columns of Table 5 by replacing $I Q I$ with six indices of the institutional quality. The squared pattern of $F F I$ is once again confirmed. Results are not reported for brevity. Attempts of implementing DREM and double correction with the six institutional indices instead of IQI turned out statistically inconclusive. Furthermore, individual institutional indices produced mixed results.
} 
We test the relationship between regulatory stringency and the risk of a crisis by subjecting a non-linear specification to Probit estimation using annual data from 1999 to 2011 drawn from 132 countries. Our key inference is that the probability of a financial crisis fits an inverted Ushaped curve: it rises as one moves from low to medium levels of regulation and falls from medium to high levels of regulation. The peak point of the probability occurs where the Financial Freedom Index, an inverse measure of regulation stringency, reaches approximately a value of 70 (out of a maximum of 100).

The peak point is surrounded to the west and to the east by areas with lower probabilities of a crisis. Countries in each of these areas find themselves in a sort of liberalization trap. To the west of the peak, a country that embarks on a liberalization process raises the probability of a crisis. When a crisis erupts, regulation tightens at the expense of efficiency and profitability. Complacency in good times restores more lenient regulations. A new cycle starts with the occurrence of another crisis. This up-and-down pattern characterizes a regulatory pendulum along a liberalization path. If, instead a crisis does not occur, the banking system continues to liberalize and may settle to the east of the peak point. The occurrence of a crisis triggers regulatory stringency, but this is resisted because it raises the probability of a crisis, while increasing inefficiency and lowering profitability. Up-and-down swings can occur also on the east of the peak point until a massive crisis-e.g., the Great Depression of the 1930sforces re-regulation and displaces a country from the east side to the west side of the peak point for a long time.

Countries with medium level of regulatory stringency that cluster around the peak, mostly European countries, have incentive to move either to the east or to the west of the peak to reduce the probability of a crisis. Those with good institutions have an incentive to move to the east because the quality of institutions attenuates the loss given default. Those with poor 
institutions have instead an incentives to tighten regulation. Either way, the position around the peak is unstable.

Liberalization traps exacerbate coordination problems when a trade-off can be made between regulation stringency and institutional quality. Common international regulatory standards resolve the coordination problem if participating countries have common preferences and similar quality of institutions; otherwise the agreement is likely to be inferior to a domestic solution where trade-offs can be made between regulatory stringency and institutional quality. Brexit is a case in point of contrasting views on banking regulation between the UK and the EU. According to the Financial Freedom Index, the UK has a much higher score than EU continental countries. It follows that the UK can minimize the probability of a crisis with a more liberal regulatory environment than prevails in many continental European countries. The common regulatory structure existing in the EU cannot resolve the conflict, unless all member countries are willing to undertake the same institutional reforms. Differences in national regulatory preferences may have played a role in the Brexit outcome; and paradoxically, without the UK, the adoption of a stricter regulation in the EU could become not only easier but also more effective.

\section{References}

Abiad, A., Detragiache, E., Tressel, T. (2010). A New Database of Financial Reforms, IMF Staff Papers, 57(2):281-303

Ai, C., Norton, E. C. (2003). Interaction terms in logit and probit models. Economics Letters, 80(1), 123-129.

Aizenman, J. (2009). Financial Crisis and the Paradox of Under - and Over-Regulation, NBER WP n.15018; in Annual World Bank Conference on Development Economics, Volume, eds. Lin and Pleskovic, 2011.

Anginer, D., Demirgüç-Kunt, A., Zhu, M. (2014). How does competition affect bank systemic risk? Journal of Financial Intermediation, 23(1), pp. 1-26.

Barrell, R., Davis, E. P., Karim, D. \& Liazde, I. (2010). Bank regulation, property prices and early warning systems for banking crises in OECD countries. Journal of Banking \& Finance, 34 (9), pp. 2255-2264. 
Barth, J. R., Caprio, G., Levine, R. (2001). Banking systems around the globe: Do regulation and ownership affect performance and stability? In Mishkin, F. S. Prudential supervision: What works and what doesn't (pp. 31-96). Chicago: University of Chicago Press.

Barth, J.R., Caprio, G., Levine, R. (2004). Bank regulation and supervision: What works best? Journal of Financial Intermediation, 13(2), 205-248.

Barth, J.R., Caprio, G., Levine, R. (2013) "Bank regulation and supervision in 180 countries from 1999 to 2011", Journal of Financial Economic Policy, Vol. 5 Issue: 2, pp.111-219

Beck, T., Demirgüç-Kunt, A., Levine, R. (2003). Law and finance: Why does legal origin matter? Journal of Comparative Economics, 31(4):653-675.

Beck, T., De Jonghe, O., Schepens, G. (2013). Bank competition and stability: Cross-country heterogeneity. Journal of Financial Intermediation. 22(2), pp. 218-244.

Beker, V. A., Moro, B. (2016). Modern financial crises: Argentina, United States and Europe. Springer International Publishing.

Berger, A. N., Bouwman, C. H. S., Kick, T., Schaeck, K. (2016) Bank liquidity creation following regulatory interventions and capital support. Journal of Financial Intermediation, Vol. 26, pp. 115-141.

Bjornskov, C. (2016). Economic freedom and economic crises, European Journal of Political Economy, $\mathrm{xxx}(2016) \mathrm{xxx}-\mathrm{xxx}$ (forthcoming)

Bordo, M., Eichengreen, B., Klingebiel, D., Martinez Peria, M.S. (2001). Is the Crisis Problem Growing More Severe?, Economic Policy, 16:51-82

Caprio, G., Klingebiel, D., Laeven, L., Noguera,G. (2005), "Appendix: Banking Crisis Database". In Patrick Honohan and Luc Laeven (eds.), Systemic Financial Crises: Containment and Resolution. Cambridge: Cambridge University Press.

Chaudron, R., Haan, J. D. (2014). Identifying and Dating Systemic Banking Crises Using Incidence and Size of Bank Failures. DNB Working Papers, 406.

Chortareas, G.E., Girardone, C., Ventouri, A. (2013). Financial freedom and bank efficiency: Evidence from the European Union, Journal of Banking \& Finance, 37(2013):1223-1231.

Cubillas, E., Gonzalez, F. (2014). Financial liberalization and bank risk-taking: International evidence, Journal of Financial Stability, 11(2014):32-48

Daniel, B.C., Jones, J.B. (2007). Financial Liberalization and Banking Crises in Emerging Economies, Journal of International Economics, 72(1):202-221.

De Rynck, S. (2015). Banking on a union: The politics of changing eurozone banking supervision. Journal of European Public Policy, 23(1):1-17.

Delis, M.D. (2012). Bank competition, financial reform, and institutions: The importance of being developed, Journal of Development Economics, 97(2012):450-465

Demirgüç-Kunt, A., Detragiache, E. (1998). The Determinants of Banking Crises in Developing and Developed Countries. Staff Papers - International Monetary Fund, 45(1), 81.

Demirgüç-Kunt, A., Detragiache, E. (2010). Basel Core Principles and Bank Risk: Does Compliance Matter? IMF Working Papers, 10(81):1-28. 
Demirgüç-Kunt, A., Detragiache, E., Tressel, T. (2008). Banking on the principles: Compliance with Basel Core Principles and bank soundness. Journal of Financial Intermediation, 17(4):511-542.

Fratianni, M., Marchionne, F. (2013). The fading stock market response to announcements of bank bailouts. Journal of Financial Stability, 9(2013):69- 89

Fratianni, M., Marchionne, F. (2016). Bank asset reallocation and sovereign debt, Journal of International Financial Markets, Institutions \& Money, forthcoming.

Fratzscher, M., König, P. J., Lambert, C. (2016). Credit provision and banking stability after the Great Financial Crisis: The role of bank regulation and the quality of governance. Journal of International Money and Finance, Vol. 66, pp. 113-135.

Global Financial Development Database (GFDD). The World Bank (2016), available online at: $\quad$ http://www.worldbank.org/en/publication/gfdr/data/global-financial-developmentdatabase.

Goetz, M. R. (2017). Competition and bank stability. Journal of Financial Intermediation, forthcoming, https://doi.org/10.1016/j.jfi.2017.06.001.

González, F. (2005). Bank regulation and risk-taking incentives: An international comparison of bank risk. Journal of Banking \& Finance, 29(5):1153-1184.

Greene, W. (2004). The behaviour of the maximum likelihood estimator of limited dependent variable models in the presence of fixed effects. Econometrics Journal, 7(1):98-119

Greene, W. (2010). Testing hypotheses about interaction terms in nonlinear models. Economics Letters, 107(2):291-296.

Heritage Foundation (2016). 2016 About the index, Index of Economic Freedom, available online at: http://www.heritage.org/index/book/methodology.

Hutchison, M., McDill, K. (1999). Are All Banking Crises Alike? The Japanese Experience in International Comparison. Journal of the Japanese and International Economies, 13(3):155-180.

Kaminsky, G.L., Reinhart, C.M. (1999) The Twin Crises: The Causes of Banking and Balance of Payments Problems, American Economic Review, 89(3):473-500.

Keeley, M.C. (1990). Deposit insurance, risk and market power in banking, American Economic Review, 80:1183-1200.

Klomp, J., de Haan, J. (2014). Bank Regulation, the Quality of Institutions, and Banking Risk in Emerging and Developing Countries: An Empirical Analysis. Emerging Markets Finance and Trade, 50(6):19-40.

La Porta, R., Lopez-de-Silanes, F., Shleifer, A., \& Vishny, R. (1999). The Quality of Government. Journal of Law, Economics and Organization, 15(1):222-279.

Laeven, L., Valencia, F. (2013). Systemic Banking Crises Database. IMF Economic Review, 61(2):225-270.

Lambert, C., Noth, C., Schüwer, U. (2017). How do insured deposits affect bank risk? Evidence from the 2008 Emergency Economic Stabilization Act. Journal of Financial Intermediation, Vol. 29, pp. 81-102.

Lee, C.-C., Lin, C.-W., Zeng, J.-H. (2016). Financial liberalization, insurance market, and the likelihood of financial crises. Journal of International Money and Finance, Vol. 62, pp. 2551 . 
Lee, K., Lu, W. (2015). Do bank regulation and supervision matter? Journal of Financial Economic Policy, 7(3):275-288.

Marchionne, F., Zazzaro, A. (2013). Risk and Competitiveness in the Italian banking sector, mimeo.

McKinnon, R. (1973), Money and Capital in Economic Development. Washington, D.C.:

Mishkin, F. S. (1999). Lessons from the Tequila Crisis. Journal of Banking \& Finance, 23(10):1521-1533.

OECD (2006). Competition and regulation in retail banking. OECD Journal: Competition Law and Policy, DAF/COMP(2006)33.

OECD (2011). Bank competition and financial stability. Paris: OECD Publishing.

Podpiera, R. (2006). Does Compliance with Basel Core Principles Bring Any Measurable Benefits? IMF Staff Papers, 53(2):306-325.

Reinhart, C., Rogoff, K. (2008). This Time is Different: A Panoramic View of Eight Centuries of Financial Crises, Harvard.

Shaw, E. (1973). Financial Deepening in Economic Development. New York: Oxford University Press.

Sundararajan, V., Marston, D., Basu, R. (2001). Financial System Standards and Financial Stability: The Case of Basel Core Principles. IMF Working Papers, 01(62):1-33.

Tchana Tchana, F. (2014). The empirics of banking regulation. Emerging Markets Review, 19:49-76.

Wooldridge, J.M. (2005). Simple solutions to the initial conditions problem in dynamic, nonlinear panel data models with unobserved heterogeneity. Journal of Applied Econometrics, 20(1):39-54.

Wooldridge, J.M. (2010). Correlated Random Effects Models with Unbalanced Panels. Department of Economics Michigan State University.

World Development Indicator . The World Bank (2016). Retrieved September 13, 2016, from http://data.worldbank.org/data-catalog/world-development-indicators.

Worldwide Governance Indicators. The World Bank (2015). Retrieved September 13, 2016, from http://data.worldbank.org/data-catalog/worldwide-governance-indicators.

Zazzaro, A., Presbitero, A., Papi, L. (2015). IMF Lending and Banking Crises, IMF Economic Review, 63(3):644-691. 
Table 1: Descriptive statistics

\begin{tabular}{lrrrrrrr}
\hline Variables & Mean & Std. Dev. & Min & Median & Max & \multicolumn{1}{c}{ Coeff. Var. } \\
\hline CRISIS & 0.070 & 0.255 & 0 & 0 & 1 & 3.649 \\
ALL_CRISIS & 0.077 & 0.266 & 0 & 0 & 1 & 3.466 \\
GDPpc & 1.164 & 1.911 & 0.006 & 0.356 & 19.365 & 1.641 \\
BAS & 52.032 & 43.420 & 0.501 & 39.180 & 263.126 & 0.834 \\
INF & 18.666 & 417.559 & -35.837 & 4.179 & 24,411 & 22.369 \\
CAB & -2.788 & 15.180 & -147.99 & -3.188 & 291.318 & -5.445 \\
TOP5 & 81.699 & 16.197 & 23.182 & 85.338 & 100 & 0.198 \\
ENGLISH & 0.347 & 0.476 & 0 & 0 & 1 & 1.371 \\
MUSLIM & 22.076 & 35.329 & 0 & 1 & 99.900 & 1.600 \\
EU & 0.101 & 0.302 & 0 & 0 & 1 & 2.971 \\
EURO & 0.054 & 0.227 & 0 & 0 & 1 & 4.150 \\
PERIOD & 0.404 & 0.490 & 0 & 0 & 1 & 1.212 \\
FFI & 49.983 & 20.073 & 0 & 50 & 90 & 0.402 \\
IQI & 0.532 & 0.195 & 0.021 & 0.500 & 0.959 & 0.366 \\
\hline
\end{tabular}

NOTES: Period: 1999-2011. PERIOD identifies the starting year of the Great Financial Crisis (2008). EU $=1$ for EU member country; EURO = 1 for Eurozone member country. See Appendix B for the complete list of variable definitions and sources.

Table 2: Sub-samples, pre-crisis, crisis, EU vs. non-EU countries

\begin{tabular}{|c|c|c|c|c|c|}
\hline \multirow[b]{2}{*}{ Variables } & \multicolumn{2}{|c|}{ Panel A: Pre-Crisis } & \multicolumn{2}{|c|}{ Panel B: Crisis } & \multirow{2}{*}{$\begin{array}{c}\text { Panel C: EU } \\
\text { Pre-Crisis vs } \\
\text { Crisis } \\
(5)\end{array}$} \\
\hline & Non-EU & $\begin{array}{r}\mathbf{E U} \\
(2)\end{array}$ & $\begin{array}{c}\text { Non-EU } \\
\text { (3) }\end{array}$ & $\begin{array}{r}\mathbf{E U} \\
(4)\end{array}$ & \\
\hline Panel A & Mean & Mean $^{a}$ & Mean & Mean $^{a}$ & Mean $^{a}$ \\
\hline$I Q I$ & 0.499 & $0.811 * * *$ & 0.498 & $0.764 * * *$ & $* * *$ \\
\hline GDPpc & 0.773 & $2.798 * * *$ & 1.194 & $3.356 * * *$ & $* * *$ \\
\hline$B A S$ & 41.727 & $95.494 * * *$ & 51.455 & $113.787 * * *$ & $* * *$ \\
\hline INF & 29.890 & $2.534 * *$ & 6.264 & $1.982 * * *$ & $* *$ \\
\hline$C A B$ & -2.969 & $-1.158 * * *$ & -3.308 & $-0.199 * * *$ & $*$ \\
\hline TOP5 & 81.806 & 82.156 & 80.964 & $83.412 * *$ & \\
\hline$F F I$ & 48.349 & $69.396^{* * *}$ & 45.153 & $69.271^{* * *}$ & \\
\hline Panel B & Median & Median $^{b}$ & Median & Median $^{\text {b }}$ & Median $^{b}$ \\
\hline$I Q I$ & 0.473 & $0.814 * * *$ & 0.474 & $0.757 * * *$ & $* * *$ \\
\hline GDPpc & 0.207 & $2.628 * * *$ & 0.412 & $2.886^{* * *}$ & $* *$ \\
\hline$B A S$ & 31.670 & $93.658 * * *$ & 40.480 & $105.027 * * *$ & $* * *$ \\
\hline$I N F$ & 5.174 & $2.215 * * *$ & 4.624 & $1.692 * * *$ & $* * *$ \\
\hline$C A B$ & -3.341 & $-0.519 * * *$ & $-4.516^{* * *}$ & -0.114 & \\
\hline TOP5 & 85.708 & 86.053 & 83.603 & 87.234 & \\
\hline $\boldsymbol{F F I}$ & 50 & $70 * * *$ & 50 & $70 * * *$ & \\
\hline
\end{tabular}

NOTES: Period $=1999-2011$, pre-crisis $=1999-2006$, crisis $=2008-2011$. See Appendix B for the complete list of variable definitions and sources. (a) Mean-comparison test against the previous sub-sample for mean; (b) Wilcoxon rank-sum test against the previous sub-sample for medians. ${ }^{* *} \mathrm{p}<0.01,{ }^{* *} \mathrm{p}<0.05,{ }^{*} \mathrm{p}<0.1$. 
Table 3: Different specifications of the benchmark model, pooled Probit regressions

\begin{tabular}{|c|c|c|c|c|c|c|c|}
\hline VARIABLES & $\begin{array}{c}\text { Base } \\
\text { (1) }\end{array}$ & $\begin{array}{c}\text { HYP1 } \\
(2) \\
\end{array}$ & $\begin{array}{c}\text { HYP2 } \\
\text { (3) } \\
\end{array}$ & $\begin{array}{c}\text { HYP1 } \\
\text { (4) } \\
\end{array}$ & $\begin{array}{c}\text { HYP2 } \\
(5) \\
\end{array}$ & $\begin{array}{c}\text { Abiad et } \\
\text { al. } \\
(6)^{\mathrm{a}}\end{array}$ & $\begin{array}{c}\text { Barth et al. } \\
(7)^{\mathbf{b}} \\
\end{array}$ \\
\hline L.GDPpc & $0.1971 * * *$ & $0.2105^{* * *}$ & $0.2379 * * *$ & $0.2574 * * *$ & $0.2922 * * *$ & 0.1936 & $0.2446 * * *$ \\
\hline L.TOP5 & $-0.0147 * * *$ & $-0.0140 * * *$ & $-0.0148 * * *$ & $-0.0130 * * *$ & $-0.0142 * * *$ & $-0.0193 * *$ & $-0.0181 * * *$ \\
\hline$I Q I$ & -0.5882 & $-1.1975^{*}$ & $-1.4296^{* *}$ & $-1.1598 \#$ & $-1.4596^{*}$ & $3.6494 * *$ & -0.6103 \\
\hline PERIOD & $0.8982 * * *$ & $0.9030 * * *$ & $0.8586 * * *$ & $0.9151 * * *$ & $0.8671 * * *$ & & $1.2413 * * *$ \\
\hline$E \boldsymbol{U}$ & $0.9626^{* * *}$ & $0.9448 * * *$ & $0.9701 * * *$ & $0.9189 * * *$ & $0.9444 * * *$ & & $0.8307 * * *$ \\
\hline L.INF & & & & $0.0128 * * *$ & $0.0138 * * *$ & $0.0205 * * *$ & $0.0111 * * *$ \\
\hline L. $C A B$ & & & & -0.0029 & -0.0017 & -0.0037 & -0.0038 \\
\hline L.FFI & & 0.0063 & $0.0564 * *$ & 0.0046 & $0.0670 * * *$ & $1.0850 * * *$ & $0.0818 * * *$ \\
\hline L.FFI2 & & & $-0.0004 * *$ & & $-0.0005 * * *$ & $-0.0079 * * *$ & $-0.0007 * * *$ \\
\hline Constant & $-0.9603 * *$ & $-1.0187 * *$ & $-2.2061 * * *$ & $-1.1583 * * *$ & $-2.6404 * * *$ & $-38.944 * * *$ & $-3.1722 * * *$ \\
\hline Observations & 1,312 & 1,246 & 1,246 & 1,138 & 1,138 & 431 & 948 \\
\hline Pseudo $R^{2}$ & 0.302 & 0.299 & 0.307 & 0.316 & 0.327 & 0.303 & 0.394 \\
\hline LL Model & -270.6 & -267.2 & -264 & -251.7 & -247.6 & -49.94 & -189.7 \\
\hline AIC & 553.1 & 548.3 & 544.1 & 521.4 & 515.3 & 115.9 & 399.4 \\
\hline BIC & 584.2 & 584.2 & 585.1 & 566.7 & 565.7 & 148.4 & 447.9 \\
\hline $\mathbf{F}^{\mathrm{ALL}}$ & 88.28 & 86.23 & 82.86 & 75.30 & 72.75 & 5.340 & 77.06 \\
\hline $\operatorname{Prob}\left(F^{\mathrm{ALL}}\right)>F$ & 0 & 0 & 0 & 0 & 0 & 0.021 & 0 \\
\hline $\mathbf{F}^{\mathrm{FFI}}$ & - & 2.047 & 6.874 & 0.955 & 7.527 & 10.61 & 12.63 \\
\hline $\operatorname{Prob}\left(F^{\mathrm{FFI}}\right)>F$ & - & 0.153 & 0.0320 & 0.329 & 0.0230 & 0.005 & 0.002 \\
\hline
\end{tabular}

NOTES: Period $=1999-2011$. Dependent variable $C R I S I S=1$ for a banking crisis occurred, 0 otherwise. PERIOD identifies the starting year of the Great Financial Crisis (2008). $E U=1$ for EU member country, 0 otherwise. Prefix $L$ indicates a one-year lagged variable. See Appendix B for the complete list of variable definitions and sources. (a) FFI is replaced with the FFI-rescaled liberalization index from Abiad et al. (2010). (b) FFI is replaced with the FFI-rescaled liberalization index from Barth et al. (2013). Pseudo $\mathrm{R}^{2}$ and LL Model report McFadden's $\mathrm{R}^{2}$ and the log-likelihood function of the model. $\mathrm{AIC}$ and BIC refers to Akaike and Bayesian Information Criterion. $F^{A L L}$ is the statistics of the full specification F-test. $F^{F F I}$ is the statistics of a joint F-test on FFI terms. ${ }^{* *} \mathrm{p}<0.01,{ }^{*} \mathrm{p}<0.05,{ }^{*} \mathrm{p}<0.10$, $\# \mathrm{p}<0.15$. 
Table 4: Different specifications of the benchmark model, pooled Probit regressions

\begin{tabular}{|c|c|c|c|c|c|c|c|c|}
\hline VARIABLES & $\begin{array}{c}\text { (1) } \\
\text { CRISIS }\end{array}$ & $\begin{array}{c}\text { (2) } \\
\text { CRISIS }\end{array}$ & $\begin{array}{c}\text { (3) } \\
\text { CRISIS }\end{array}$ & $\begin{array}{c}\text { (4) } \\
\text { CRISIS }\end{array}$ & $\begin{array}{c}\text { (5) } \\
\text { CRISIS } \\
\end{array}$ & $\begin{array}{c}\text { (6) } \\
\text { CRISIS }\end{array}$ & $\begin{array}{c}\text { (7) } \\
\text { CRISIS }\end{array}$ & $\begin{array}{c}\text { (8) } \\
\text { ALL_CRISIS } \\
\end{array}$ \\
\hline L.GDPpc & $0.2922 * * *$ & $0.3407 * * *$ & $0.2357 * * *$ & $0.3138 * * *$ & $0.2622 * * *$ & $0.3290 * * *$ & $0.3270 * * *$ & $0.2895 * * *$ \\
\hline L.TOP5 & $-0.0142 * * *$ & $-0.0123 * * *$ & $-0.0139 * * *$ & $-0.0117 * * *$ & $-0.0132 * * *$ & $-0.0126^{* *}$ & $-0.0125 * *$ & $-0.0137 * * *$ \\
\hline$I Q I$ & $-1.4596^{*}$ & $-2.8761 * * *$ & -0.5051 & $-2.2387 * * *$ & $-1.2520 \#$ & $-2.6703 * * *$ & $-2.6543 * * *$ & $-1.6393 * *$ \\
\hline PERIOD & $0.8671 * * *$ & $0.8357 * * *$ & $0.9455^{* * *}$ & $0.8897 * * *$ & $0.4587 * * *$ & $1.0307 * * *$ & $1.0054 * * *$ & $0.8070 * * *$ \\
\hline $\boldsymbol{E} \boldsymbol{U}$ & $0.9444 * * *$ & $0.6432 * * *$ & & & $0.5961 * * *$ & $1.0445 * * *$ & $1.0248 * * *$ & $0.9387 * * *$ \\
\hline L.BAS & & $0.0075 * * *$ & & $0.0076^{* * *}$ & & & & \\
\hline ENGLISH & & $-0.4267 * *$ & & $-0.5198 * * *$ & & & & \\
\hline MUSLIM & & $-0.0065 * *$ & & $-0.0067 * *$ & & & & \\
\hline L.INF & $0.0138 * * *$ & $0.0141 * * *$ & $0.0141 * * *$ & $0.0143 * * *$ & $0.0118 * * *$ & $0.0148 * * *$ & $0.0146 * * *$ & $0.0153 * * *$ \\
\hline L.CAB & -0.0017 & -0.0000 & -0.0045 & -0.0034 & 0.0005 & -0.0054 & -0.0052 & 0.0003 \\
\hline L.FFI & $0.0670 * * *$ & $0.0727 * * *$ & $0.0556 * *$ & $0.0642 * *$ & $0.0536 * *$ & $0.1233 * * *$ & $0.1216 * * *$ & $0.0551 * *$ \\
\hline L.FFI2 & $-0.0005 * * *$ & $-0.0006 * * *$ & $-0.0004 * *$ & $-0.0005 * *$ & $-0.0004 * *$ & $-0.0009 * * *$ & $-0.0009 * * *$ & $-0.0004 * *$ \\
\hline EURO & & & $0.7583 * * *$ & $0.4447 * *$ & & & & \\
\hline L.CONTAGION & & & & & $0.0523 * * *$ & & 0.0031 & \\
\hline L.TREND & & & & & & $1.0034 * * *$ & $0.9937 * * *$ & \\
\hline Constant & $-2.6404 * * *$ & $-2.4221 * * *$ & $-2.8510 * * *$ & $-2.5605 * * *$ & $-2.3445 * * *$ & $-4.7176 * * *$ & $-4.6638 * * *$ & $-2.0991 * * *$ \\
\hline Observations & 1,138 & 1,111 & 1,138 & 1,111 & 1138 & 1138 & 1138 & 1,138 \\
\hline Pseudo $\mathbf{R}^{2}$ & 0.327 & 0.374 & 0.308 & 0.365 & 0.383 & 0.607 & 0.607 & 0.300 \\
\hline LL Model & -247.6 & -227.4 & -254.6 & -230.7 & -227.1 & -144.7 & -144.7 & -268.3 \\
\hline AIC & 515.3 & 480.9 & 529.2 & 487.3 & 476.2 & 311.4 & 313.3 & 556.7 \\
\hline BIC & 565.7 & 546.1 & 579.6 & 552.5 & 531.6 & 366.8 & 373.8 & 607.1 \\
\hline $\mathbf{F}^{\mathrm{ALL}}$ & 72.75 & 72.26 & 61.28 & 67.40 & 20.00 & 53.90 & 40.43 & 73.05 \\
\hline $\operatorname{Prob}\left(F^{\mathrm{ALL}}\right)>F$ & 0 & 0 & 0 & 0 & 0 & 0 & 0 & 0 \\
\hline $\mathbf{F}^{\mathrm{FFI}}$ & 7.527 & 7.865 & 6.682 & 6.975 & 5.024 & 10.84 & 10.33 & 6.529 \\
\hline $\operatorname{Prob}\left(\mathbf{F}^{\mathrm{FFI}}\right)>\mathbf{F}$ & 0.0230 & 0.0200 & 0.0350 & 0.0310 & 0.0810 & 0.00400 & 0.00600 & 0.0380 \\
\hline
\end{tabular}

NOTES: Period = 1999-2011. CRISIS = 1 banking crisis 0 otherwise. ALL_CRISIS $=1$ banking, sovereign debt crisis or twin crises, 0 otherwise. PERIOD = starting year of the Great Financial Crisis (2008). $E U=1$ EU member country, 0 otherwise. EURO $=1$ Eurozone member country, 0 otherwise. Prefix $L$ indicates a one-year lagged variable. See Appendix B for the complete list of variables. Pseudo R ${ }^{2}$ and LL Model report McFadden's R ${ }^{2}$ and the log-likelihood function of the model. AIC and BIC refers to Akaike and Bayesian Information Criterion. $F^{A L L}$ is the statistics of the full specification $\mathrm{F}$-test. $F^{F F I}$ is the statistics of a joint $\mathrm{F}$-test on $F F I$ terms. $* * * \mathrm{p}<0.01, * * \mathrm{p}<0.05$, $* \mathrm{p}<0.10, \# \mathrm{p}<0.15$. 
Table 5: Correlated Random Effects Model (CREM), Dynamic Random Effects Model (DREM)

\begin{tabular}{|c|c|c|c|c|c|c|}
\hline VARIABLES & $\begin{array}{c}\text { LINEAR } \\
\text { CREM } \\
\text { (1) }\end{array}$ & $\begin{array}{c}\text { QUADRATIC } \\
\text { CREM } \\
\text { (2) }\end{array}$ & $\begin{array}{l}\text { LINEAR } \\
\text { DREM } \\
\text { (3) }\end{array}$ & $\begin{array}{c}\text { QUADRATIC } \\
\text { DREM } \\
(4) \\
\end{array}$ & $\begin{array}{c}\text { LINEAR } \\
\text { DCOR } \\
(5)\end{array}$ & $\begin{array}{c}\text { QUADRATIC } \\
\text { DCOR } \\
(6)\end{array}$ \\
\hline L.CRISIS & & & $3.9936^{* * *}$ & $4.0321 * * *$ & $3.6467 * * *$ & $3.6163 * * *$ \\
\hline CRISIS_t0 & & & -0.5552 & -0.5162 & -0.4518 & -0.5178 \\
\hline L.GDPpc & $2.5409 * * *$ & $2.4839 * * *$ & $0.4528 * *$ & $0.5347 * * *$ & $1.2816^{* *}$ & $1.3929 * *$ \\
\hline L.TOP5 & 0.0102 & 0.0055 & $-0.0132 *$ & $-0.0159 *$ & -0.0004 & -0.0028 \\
\hline PERIOD & 0.2771 & 0.1474 & 4.3655 & 4.8384 & 4.9704 & 4.4612 \\
\hline $\boldsymbol{E} \boldsymbol{U}$ & $-1.3285 \#$ & -0.9927 & $0.9780 * *$ & $1.0075^{* *}$ & $1.0011 * *$ & $1.0352 * *$ \\
\hline$I Q I$ & $-30.4417 * * *$ & $-31.3375^{* * *}$ & $-3.5937^{*}$ & $-4.0343 * *$ & $-11.6559 \#$ & $-12.4479 *$ \\
\hline L.BAS & $0.1208 * * *$ & $0.1166^{* * *}$ & 0.0024 & 0.0026 & $0.0442 * * *$ & $0.0406 * * *$ \\
\hline L.INF & $0.0447 * * *$ & $0.0465 * * *$ & 0.0077 & $0.0096 \#$ & 0.0067 & 0.0056 \\
\hline L.CAB & -0.0282 & -0.0328 & -0.0156 & -0.016 & 0.0062 & 0.0037 \\
\hline L.FFI & 0.0114 & $0.1546 *$ & 0.0132 & $0.1092 *$ & 0.0214 & $0.2204 * * *$ \\
\hline L.FFI2 & & $-0.0013 *$ & & $-0.0008 *$ & & $-0.0018 * * *$ \\
\hline Constant & $2.1744 * * *$ & $1.9044 * * *$ & -1.1679 & -0.9582 & -0.7791 & -2.1697 \\
\hline Ln(Sigma_u) & -0.6987 & $-7.7844 \#$ & $810.7109^{* *}$ & $775.1260 *$ & $830.2068^{*}$ & $795.3353^{*}$ \\
\hline Within-Country & Yes & Yes & No & No & Yes & Yes \\
\hline Time-Average & No & No & Yes & Yes & Yes & Yes \\
\hline Observations & 1115 & 1115 & 1115 & 1115 & 1115 & 1115 \\
\hline Nr. of countries & 132 & 132 & 132 & 132 & 132 & 132 \\
\hline Pseudo $\mathbf{R}^{2}$ & 0.208 & 0.171 & 0.01 & 0.013 & 0.011 & 0.001 \\
\hline Sigma_u & 2.9660 & 2.5912 & 0.5912 & 0.6184 & 0.6773 & 0.3380 \\
\hline Rho & 0.8979 & 0.8704 & 0.2590 & 0.2767 & 0.3145 & 0.1025 \\
\hline LL Model & -147 & -143.9 & -89.95 & -87.77 & -77.23 & -73.13 \\
\hline AIC & 330 & 327.9 & 219.9 & 219.5 & 208.5 & 206.3 \\
\hline BIC & 420.3 & 428.2 & 320.2 & 329.9 & 343.9 & 356.7 \\
\hline$F^{\text {ALL }}$ & 21.07 & 19.37 & 12.22 & 11.35 & 8.465 & 9.881 \\
\hline $\operatorname{Prob}\left(F^{\mathrm{ALL}}\right)>\mathbf{F}$ & 0 & 0.001 & 0.032 & 0.045 & 0.206 & 0.13 \\
\hline $\mathbf{F}^{\mathrm{FFI} I \mathrm{M}}$ & 1.048 & 6.709 & & & & \\
\hline $\operatorname{Prob}\left(\mathbf{F}^{\mathrm{FFI} \_\mathrm{M}}\right)>\mathbf{F}$ & 0.592 & 0.152 & & & & \\
\hline F $^{\text {FFI_T }}$ & & & 5.878 & 7.395 & & \\
\hline $\operatorname{Prob}\left(\mathbf{F}^{\mathrm{FFI}-\mathrm{T}}\right)>\mathbf{F}$ & & & 0.053 & 0.116 & & \\
\hline F FFI_MT $^{\mathrm{FI}}$ & & & & & 5.66 & 12.71 \\
\hline $\operatorname{Prob}\left(\mathrm{F}^{\mathrm{FFI} M T}\right)>\mathbf{F}$ & & & & & 0.129 & 0.048 \\
\hline $\mathbf{F}^{\text {FFI_A }}$ & 0.62 & 3.723 & 1.833 & 4.261 & 2.009 & 9.322 \\
\hline $\operatorname{Prob}\left(\mathbf{F}^{\mathrm{FFI} \_}{ }^{A}\right)>\mathbf{F}$ & 0.431 & 0.155 & 0.176 & 0.119 & 0.156 & 0.009 \\
\hline
\end{tabular}

NOTES: Probit regressions. Period: 1999-2011. CREM = Correlated Random Effects Model. $D R E M=$ Dynamic Random Effects Model . DCOR = double correction for both CREM and DREM. CRISIS $=1$ banking crisis, 0 otherwise. PERIOD identifies the starting year of the Great Financial Crisis (2008). $E U=1 \mathrm{EU}$ member country, 0 otherwise. Prefix $L$ indicates a one-year lagged variable. See Appendix B for the complete list of variables. Ln(Sigma_u) is the (logged) variance of random effects and is equivalent to 2 times the log of the standard deviation Sigma $u$. Rho is the ratio of the variance of random effects to the sum of variance of random effects and idiosyncratic error term. A Rho different from zero and a significant Ln(Sigma_u ) indicates that the panel estimate is superior to the pool estimate. Pseudo $\mathrm{R}^{2}$ and LL Model report McFadden's $\mathrm{R}^{2}$ and the log-likelihood function of the model. AIC and BIC refer to Akaike and Bayesian Information Criterion. $F^{A L L}$ is the statistics of the full specification. $F^{F F I_{-} M}, F^{F F I_{-} T}$, and $F^{F F I_{-} M T}$ are the statistics of a joint F-test for within-country Mundlakcorrection $F F I$ means, time-average Mundlak-correction of $F F I$ means, within-country and time-average Mundlak-correction of $F F I$ means. $F^{F F I} A_{-}$is the statistics of a joint F-test of $F F I$ terms and all Mundlak-correction FFI means. LL Model indicates the log-likelihood function of the model. ${ }^{* * *} \mathrm{p}<0.01,{ }^{* *} \mathrm{p}<0.05,{ }^{*} \mathrm{p}<0.10, \# \mathrm{p}<0.15$ 
Table 6: Three-year wave regressions (compare to Table 3)

\begin{tabular}{|c|c|c|c|c|c|}
\hline VARIABLES & $\begin{array}{c}\text { Base } \\
\text { (1) }\end{array}$ & $\begin{array}{c}H Y P 1 \\
(2) \\
\end{array}$ & $\begin{array}{c}\text { HYP2 } \\
\text { (3) }\end{array}$ & $\begin{array}{c}\text { HYP1 } \\
\text { (4) } \\
\end{array}$ & $\begin{array}{c}\text { HYP2 } \\
(5) \\
\end{array}$ \\
\hline GDPpc & $0.3086^{* * *}$ & $0.3277 * * *$ & $0.3780 * * *$ & $0.4289 * * *$ & $0.5015^{* * *}$ \\
\hline TOP5 & $-0.0166^{* * *}$ & $-0.0157 * * *$ & $-0.0176^{* * *}$ & $-0.0142 * *$ & $-0.0176 * * *$ \\
\hline$I Q I$ & $-1.5413 \#$ & $-1.9900 *$ & $-2.5246^{* *}$ & $-2.2267^{*}$ & $-2.9496 * *$ \\
\hline PERIOD & $0.3731 *$ & $0.3537^{*}$ & $0.3021 \#$ & $0.3212 \#$ & 0.2748 \\
\hline $\boldsymbol{E} \boldsymbol{U}$ & $1.4160 * * *$ & $1.4104 * * *$ & $1.4824 * * *$ & $1.3661 * * *$ & $1.4598 * * *$ \\
\hline$I N F$ & & & & $0.0208 * *$ & $0.0266^{* * *}$ \\
\hline$C A B$ & & & & -0.0145 & -0.0125 \\
\hline FFI & & 0.0032 & $0.0873 * *$ & 0.0025 & $0.1218 * *$ \\
\hline$F F I 2$ & & & $-0.0007 * *$ & & $-0.0010 * *$ \\
\hline Constant & -0.1116 & -0.1037 & $-2.0129 *$ & -0.2515 & $-3.0630 * *$ \\
\hline Observations & 498 & 474 & 474 & 431 & 431 \\
\hline Pseudo $\mathbf{R}^{2}$ & 0.336 & 0.331 & 0.349 & 0.358 & 0.384 \\
\hline LL Model & -109.3 & -108.2 & -105.4 & -100.6 & -96.49 \\
\hline AIC & 230.5 & 230.5 & 226.8 & 219.1 & 213 \\
\hline BIC & 255.8 & 259.6 & 260.1 & 255.7 & 253.6 \\
\hline $\mathbf{F}^{\mathrm{ALL}}$ & 84.38 & 81.87 & 80.36 & 83.41 & 81.66 \\
\hline $\operatorname{Prob}\left(F^{A L L}\right)>F$ & 0 & 0 & 0 & 0 & 0 \\
\hline $\mathbf{F}^{\mathrm{FFI}}$ & - & 0.208 & 4.609 & 0.106 & 6.347 \\
\hline $\operatorname{Prob}\left(\mathbf{F}^{\mathrm{FFI}}\right)>\mathbf{F}$ & - & 0.648 & 0.100 & 0.744 & 0.0420 \\
\hline
\end{tabular}

NOTES: Pooled Probit regressions. Period: 1999-2011. CRISIS $=1$ banking crisis, 0 otherwise. PERIOD identifies the starting year of the Great Financial Crisis (2008). $E U=1$ EU member country, 0 otherwise. Prefix $L$ indicates a one-year lagged variable. See Appendix B for the complete list of variables. Pseudo $\mathrm{R}^{2}$ and $L L$ Model report McFadden's $\mathrm{R}^{2}$ and the log-likelihood function of the model. AIC and BIC refers to Akaike and Bayesian Information Criterion. $F^{A L L}$ is the statistics of the full specification F-test. $F^{F F I}$ is the statistics of a joint F-test on FFI terms. ${ }^{* * *} \mathrm{p}<0.01,{ }^{* *} \mathrm{p}<0.05,{ }^{*} \mathrm{p}<0.10, \# \mathrm{p}<0.15$. 
Table 7: Three-year wave regressions (compare to Table 4)

\begin{tabular}{|c|c|c|c|c|c|c|c|c|}
\hline VARIABLES & $\begin{array}{c}\text { CRISIS } \\
(1) \\
\end{array}$ & $\begin{array}{c}\text { CRISIS } \\
(2) \\
\end{array}$ & $\begin{array}{c}\text { CRISIS } \\
(3) \\
\end{array}$ & $\begin{array}{c}\text { CRISIS } \\
(4) \\
\end{array}$ & $\begin{array}{c}\text { CRISIS } \\
(5) \\
\end{array}$ & $\begin{array}{c}\text { CRISIS } \\
(6) \\
\end{array}$ & $\begin{array}{c}\text { CRISIS } \\
(7) \\
\end{array}$ & $\begin{array}{c}\text { ALL_CRISIS } \\
(8)\end{array}$ \\
\hline GDPpc & $0.5015 * * *$ & $0.5411 * * *$ & $0.4116^{* * *}$ & $0.4851 * * *$ & $0.4665 * * *$ & $0.4957 * * *$ & $0.4894 * * *$ & $0.4724 * * *$ \\
\hline TOP5 & $-0.0176^{* * *}$ & $-0.0162 * *$ & $-0.0155 * * *$ & $-0.0137 * *$ & $-0.0129 * *$ & -0.0086 & -0.0082 & $-0.0170 * * *$ \\
\hline$I Q I$ & $-2.9496 * *$ & $-3.9947 * * *$ & -1.1210 & $-2.5096 * *$ & -0.8912 & -1.3300 & -1.4227 & $-2.9551 * *$ \\
\hline PERIOD & 0.2748 & 0.2749 & $0.3650 *$ & $0.3662 \#$ & $-0.5584 \#$ & -0.2588 & $-0.6025 \#$ & 0.1561 \\
\hline $\boldsymbol{E} \boldsymbol{U}$ & $1.4598 * * *$ & $1.1817 * * *$ & & & & & & $1.4540 * * *$ \\
\hline$B A S$ & & $0.0054 *$ & & $0.0060 * *$ & & & & \\
\hline ENGLISH & & -0.3938 & & $-0.5949 * *$ & & & & \\
\hline MUSLIM & & -0.0061 & & -0.0067 & & & & \\
\hline$I N F$ & $0.0266 * * *$ & $0.0277 * * *$ & $0.0260 * * *$ & $0.0274 * * *$ & $0.0214 * *$ & 0.0120 & 0.0116 & $0.0249 * * *$ \\
\hline$C A B$ & -0.0125 & -0.0123 & -0.0183 & -0.0204 & $-0.0233^{*}$ & $-0.0333 * *$ & $-0.0314 * *$ & -0.0063 \\
\hline$F F I$ & $0.1218 * *$ & $0.1301 * *$ & $0.0922 * *$ & $0.1060 * *$ & $0.0849 *$ & $0.1209 * *$ & $0.1127 * *$ & $0.0786 * *$ \\
\hline FFI2 & $-0.0010 * *$ & $-0.0010 * *$ & $-0.0007 *$ & $-0.0008 * *$ & $-0.0007 *$ & $-0.0009 * *$ & $-0.0009 * *$ & $-0.0007 * *$ \\
\hline EURO & & & $0.9440 * * *$ & $0.6117 * *$ & & & & \\
\hline L.CONTAGION & & & & & $0.0726 * * *$ & & 0.0321 & \\
\hline L.TREND & & & & & & $0.8055^{* * *}$ & $0.7315 * * *$ & \\
\hline Constant & $-3.0630 * *$ & $-3.0288 * *$ & $-3.2379 * *$ & $-3.2288 * *$ & $-3.1413 * *$ & $-4.5140 * * *$ & $-4.2314 * * *$ & -1.5374 \\
\hline Obsevations & 431 & 424 & 431 & 424 & 431 & 431 & 431 & 431 \\
\hline Pseudo $\mathbf{R}^{2}$ & 0.384 & 0.414 & 0.331 & 0.379 & 0.354 & 0.469 & 0.476 & 0.334 \\
\hline Llmodel & -96.49 & -91.35 & -104.9 & -96.82 & -101.3 & -83.15 & -82.18 & -109.6 \\
\hline AIC & 213 & 208.7 & 229.8 & 219.6 & 222.6 & 186.3 & 186.4 & 239.1 \\
\hline BIC & 253.6 & 261.4 & 270.4 & 272.3 & 263.2 & 227.0 & 231.1 & 279.8 \\
\hline $\mathbf{F}^{\mathrm{ALL}}$ & 81.66 & 79.28 & 74.74 & 74.86 & 79.76 & 91.85 & 90.26 & 81.04 \\
\hline $\operatorname{Prob}\left(F^{\mathrm{ALL}}\right)>\mathbf{F}$ & 0 & 0 & 0 & 0 & 0 & 0 & 0 & 0 \\
\hline $\mathbf{F}^{\mathrm{FFI}}$ & 6.347 & 6.154 & 4.229 & 4.613 & 3.766 & 5.003 & 4.353 & 4.567 \\
\hline $\operatorname{Prob}\left(F^{F F I}\right)>F$ & 0.0420 & 0.0460 & 0.121 & 0.100 & 0.152 & 0.0820 & 0.113 & 0.102 \\
\hline
\end{tabular}

NOTES: Pooled Probit regressions. Period $=1999-2011$. CRISIS $=1$ banking crisis, 0 otherwise. ALL_CRISIS $=1$ banking, sovereign debt or a twin crisis, 0 otherwise. PERIOD identifies the starting year of the Great Financial Crisis (2008). EU 1 EU member country, 0 otherwise. EURO $=1$ Eurozone member country, 0 otherwise. Prefix $L$ indicates a one-year lagged variable. See Appendix B for the complete list of variables and definitions. Pseudo $\mathrm{R}^{2}$ and LL Model report McFadden's $\mathrm{R}^{2}$ and the log-likelihood function of the model. AIC and BIC refers to Akaike and Bayesian Information Criterion. $F^{A L L}$ is the statistics of the full specification F-test. $F^{F F I}$ is the statistics of a joint Ftest on FFI terms. *** $\mathrm{p}<0.01, * * \mathrm{p}<0.05, * \mathrm{p}<0.10, \# \mathrm{p}<0.15$. 
Figure 1: Impact of regulation on the probability of a crisis under three scenarios.

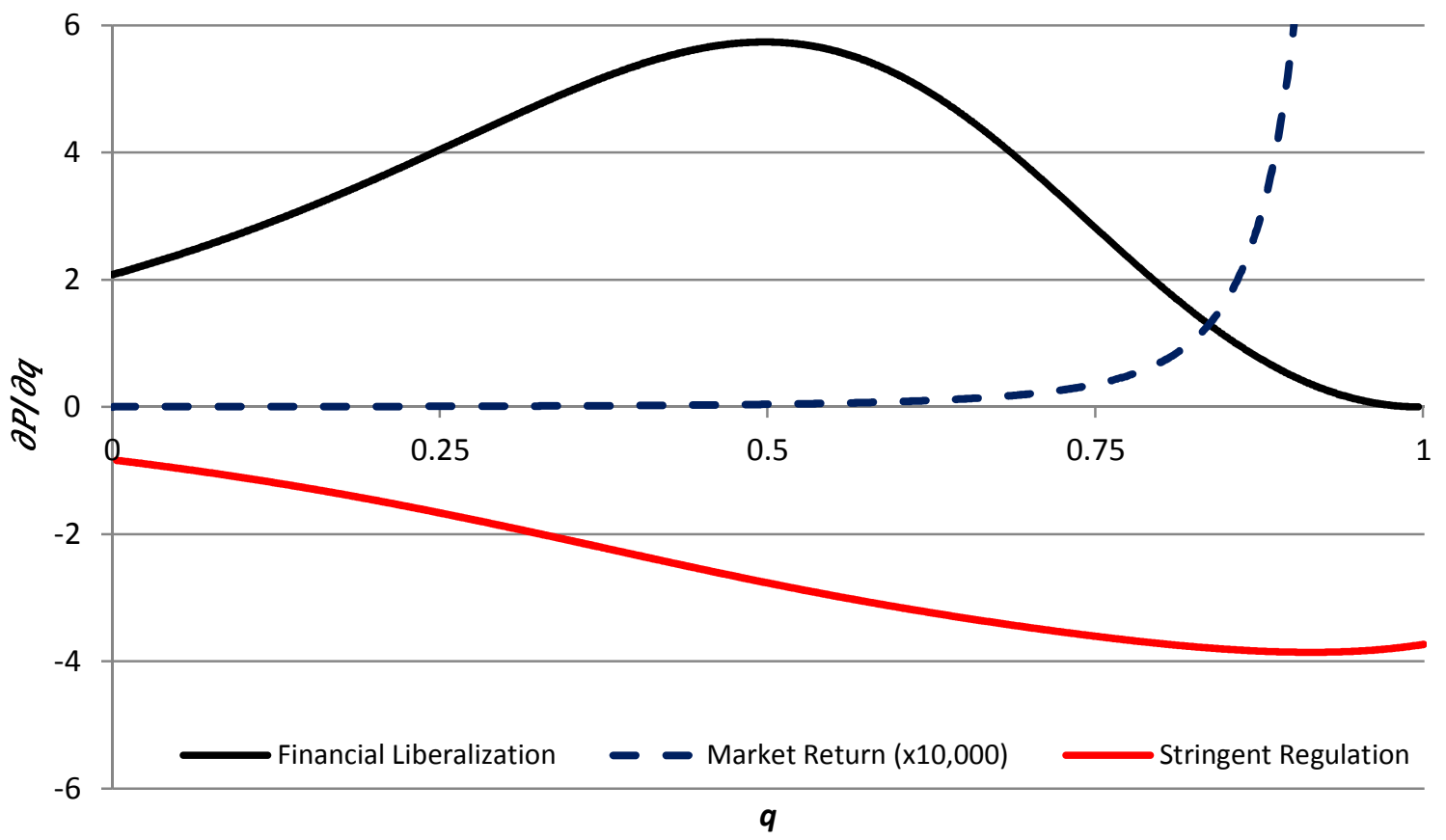

NOTES: $\frac{\partial P}{\partial q}$ is divided by 10,000 under market return scenario. Black, blue, and red curve draw respectively equation (11), (13) and (15). Scenarios are alternative: market return scenario at low levels of q, financial liberalization at medium levels of q, and stringent regulation at high levels of q. This pattern implies an inverted $\mathrm{U}$-shaped relationship between $\mathrm{q}$ and $\mathrm{P}$.

Figure 1: Number of banking crisis years measured by Financial Freedom Index.

Bank crises Financial crises

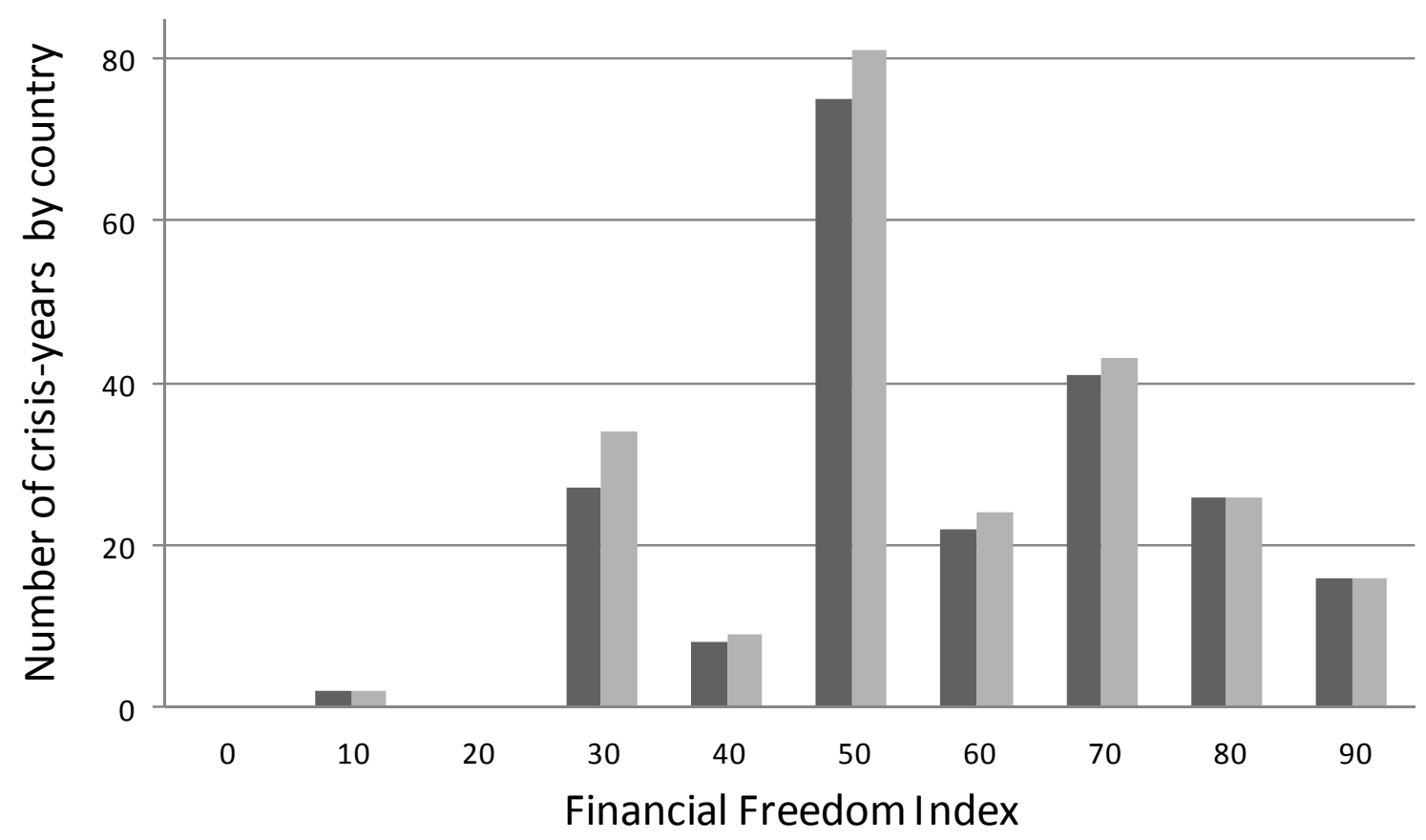


Figure 3: Impact of regulation on the probability of a banking crisis with different levels of institutional quality. Adjusted predictions for different sub-samples: pre-crisis period ( period=0), crisis period (period=1), non-EU countries $(E U=0), E U$ countries $(E U=1)$.

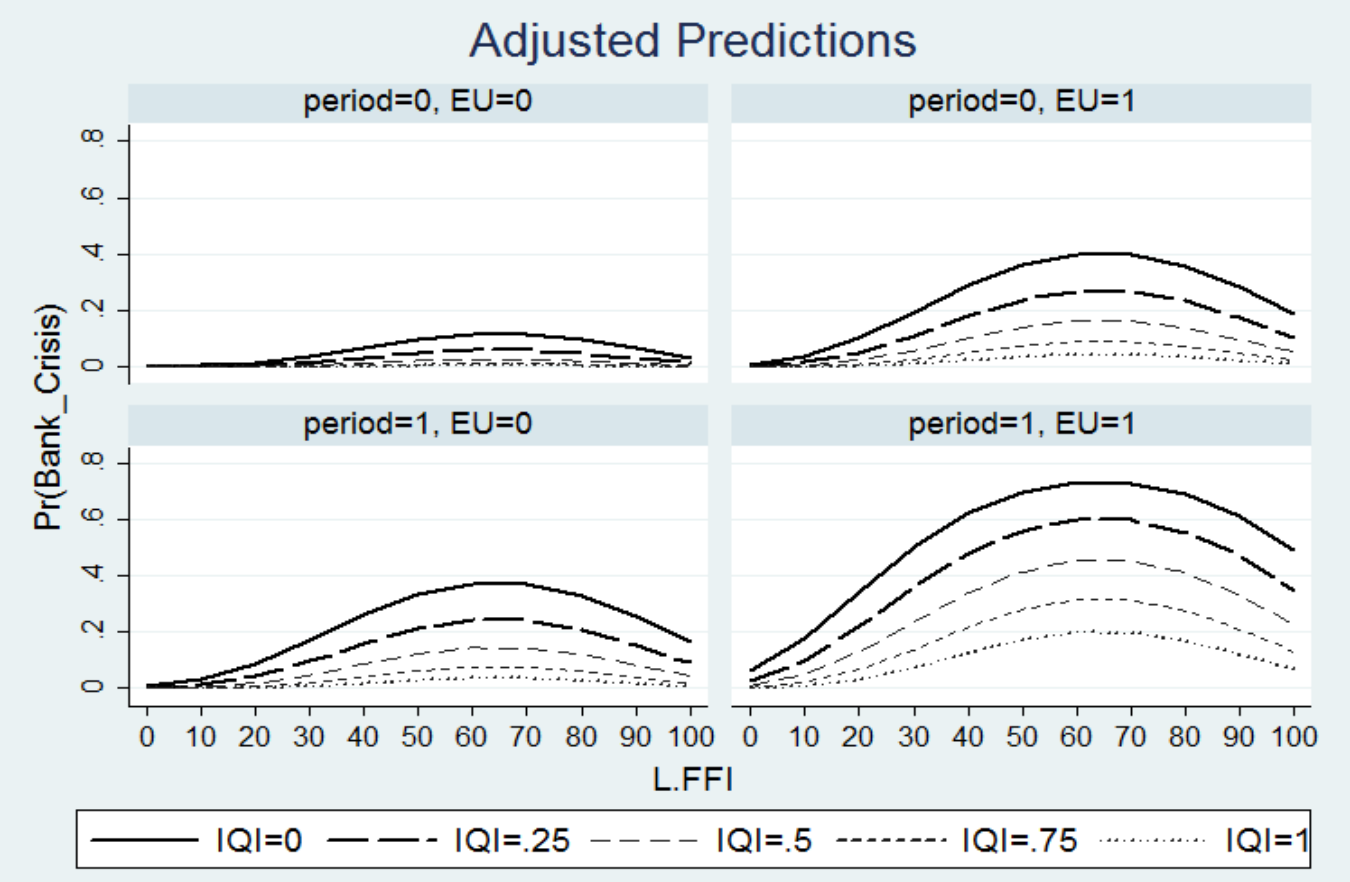

Figure 4: Impact of regulation on the probability of a banking crisis with different levels of institutional quality. Adjusted predictions for different sub-samples: pre-crisis period ( period $=0$ ), crisis period (period=1), non-EURO countries $(E U R O=0)$, EURO countries $($ EURO=1).

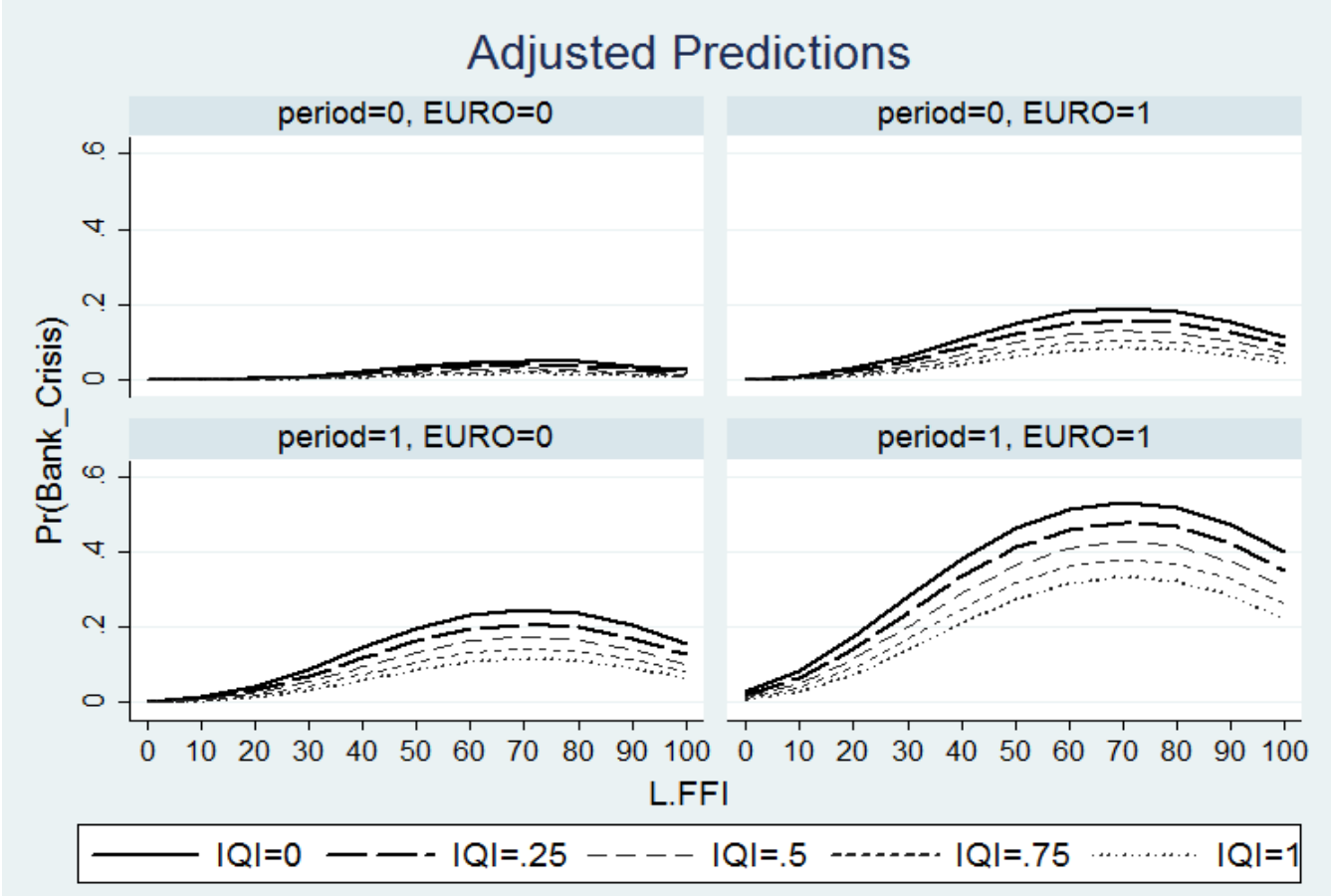




\section{APPENDIX A: Details on the theoretical model}

The minimization of the portfolio risk by the representative bank is written as

$$
\max _{\alpha}\left\{-\delta_{P}^{2}\right\} \text { s.t. }(1-q)\left[r_{L}+\alpha\left(r_{H}-r_{L}\right)\right]-\bar{r} \geq 0 \text { and } G-\alpha \geq 0 .
$$

Its Lagrangian function is:

$$
\begin{gathered}
\mathcal{L}(\alpha, \gamma, \lambda)=(1-q)^{2}\left[-\alpha^{2}\left(\delta_{H}^{2}+\delta_{L}^{2}-2 \rho_{H L} \delta_{H} \delta_{L}\right)-2 \alpha\left(\rho_{H L} \delta_{H} \delta_{L}-\delta_{L}^{2}\right)-\delta_{L}^{2}\right] \\
+\gamma\left\{(1-q)\left[r_{L}+\alpha\left(r_{H}-r_{L}\right)\right]-\bar{r}\right\}+\lambda[G-\alpha]
\end{gathered}
$$

and the Kuhn-Tucker conditions are:

$$
\begin{aligned}
& \frac{\partial \mathcal{L}}{\partial \alpha}=(1-q)^{2}\left[-2 \alpha\left(\delta_{H}^{2}+\delta_{L}^{2}-2 \rho_{H L} \delta_{H} \delta_{L}\right)-2\left(\rho_{H L} \delta_{H} \delta_{L}-\delta_{L}^{2}\right)\right]+\gamma\left(r_{H}-r_{L}\right)(1-q)-\lambda \leq 0 \\
& \left.\frac{\partial \mathcal{L}}{\partial \alpha} \alpha=\left\{(1-q)^{2} L(\alpha, \gamma, \lambda)-2\left(\rho_{H L} \delta_{H} \delta_{L}-\delta_{L}^{2}\right)\right]+\gamma\left(r_{H}-r_{L}\right)(1-q)-\lambda\right\} \alpha=0 \\
& \frac{\partial \mathcal{L}}{\partial \gamma}=\left[1+r_{L}+\alpha\left(r_{H}-r_{L}\right)\right](1-q)-(1+\bar{r}) \geq 0 \\
& \left.\frac{\partial \mathcal{L}}{\partial \gamma} \gamma=\left\{\left[r_{L}+\alpha\left(r_{H}-r_{L}\right)\right](1-q)-\bar{r}\right]\right\} \gamma=0 \\
& \frac{\partial \mathcal{L}}{\partial \lambda}=G-\alpha \geq 0 \\
& \frac{\partial \mathcal{L}}{\partial \lambda} \lambda=[G-\alpha] \lambda=0 \\
& \alpha \geq 0, \gamma \geq 0, \lambda \geq 0
\end{aligned}
$$

The system (A3)-(A9) has eight possible solutions:

1) Under financial liberalization $(\gamma=0, \lambda=0$, and $\alpha>0)$,

$$
\hat{\alpha}=\frac{\delta_{\mathrm{L}}^{2}-\rho_{\mathrm{HL}} \delta_{\mathrm{H}} \delta_{\mathrm{L}}}{\delta_{\mathrm{H}}^{2}+\delta_{\mathrm{L}}^{2}-2 \rho_{\mathrm{HL}} \delta_{\mathrm{H}} \delta_{\mathrm{L}}}
$$

and $0 \leq \hat{\alpha} \leq 1$ if $\rho_{\mathrm{HL}}<\frac{\delta_{\mathrm{L}}}{\delta_{\mathrm{H}}}$.

2) Under a binding market-imposed constraint $(\gamma>0, \lambda=0$, and $\alpha>0)$,

$$
\hat{\alpha}_{\gamma}=\frac{(1+\bar{r})-\left(1+r_{L}\right)(1-q)}{\left(r_{H}-r_{L}\right)(1-q)}=\frac{2(1-q)\left(\delta_{L}^{2}-\rho_{H L} \delta_{H} \delta_{L}\right)+\gamma\left(r_{H}-r_{L}\right)}{2(1-q)\left(\delta_{H}^{2}+\delta_{L}^{2}-2 \rho_{H L} \delta_{H} \delta_{L}\right)}
$$

and $0 \leq \alpha \leq 1$ if $-\frac{2(1-q)}{r_{H}-r_{L}}\left(\delta_{L}^{2}-\rho_{H L} \delta_{H} \delta_{L}\right) \leq \gamma \leq \frac{2(1-q)}{r_{H}-r_{L}}\left(\delta_{H}^{2}-\rho_{H L} \delta_{H} \delta_{L}\right)$.

3) Under a binding regulatory constraint $(\gamma=0, \lambda>0$, and $\alpha>0)$,

$$
\hat{\alpha}_{\lambda}=G=\frac{2(1-q)\left(\delta_{L}^{2}-\rho_{H L} \delta_{H} \delta_{L}\right)-\lambda}{2(1-q)\left(\delta_{H}^{2}+\delta_{L}^{2}-2 \rho_{H L} \delta_{H} \delta_{L}\right)}
$$

and $0 \leq \alpha \leq 1$ if $-2(1-q)^{2}\left(\delta_{H}^{2}-\rho_{H L} \delta_{H} \delta_{L}\right) \leq \gamma \leq 2(1-q)^{2}\left(\delta_{L}^{2}-\rho_{H L} \delta_{H} \delta_{L}\right)$.

4) When both constraints are binding $(\gamma>0, \lambda>0, \alpha>0)$, then both the constraints are binding. $\hat{\alpha}_{\gamma \lambda}=G=\frac{(1+\bar{r})-\left(1+r_{L}\right)(1-q)}{\left(r_{H}-r_{L}\right)(1-q)}$ is a possible solution, but the optimization degenerates to a single solution point and the bank is not free to choose $\alpha$.

5-8) In the four remaining cases ( $\alpha=0$ with $\gamma=0, \lambda=0$; or $\gamma>0, \lambda=0$; or $\gamma=0, \lambda>$ 0 ; or $\gamma>0, \lambda>0$ ), the solution is a narrow bank holding only low-risky assets. 
In a financial liberalization regime, the regulatory maximizes

$$
\max _{q} V(q)=\max _{q}(1-q)\left\{1+\beta\left[1+r_{L}+\frac{\delta_{L}^{2}-\rho_{H L} \delta_{H} \delta_{L}}{\delta_{H}^{2}+\alpha \delta_{L}^{2}-2 \rho_{H L} \delta_{H} \delta_{L}}\left(r_{H}-r_{L}\right)\right](1-P Q)\right\}
$$

From the FOC

$$
\frac{\partial V(q)}{\partial q}=-\{1+k[1-P Q]\}-(1-q) k P Q_{G}^{\prime} G_{q}^{\prime}=0
$$

with $k=\beta\left[1+r_{L}+\frac{\delta_{L}^{2}-\rho_{H L} \delta_{H} \delta_{L}}{\delta_{H}^{2}+\alpha \delta_{L}^{2}-2 \rho_{H L} \delta_{H} \delta_{L}}\left(r_{H}-r_{L}\right)\right]>0$, we obtain:

$$
P=\frac{1+k}{k} \cdot \frac{1}{\left[Q-(1-q) Q_{G}^{\prime} G_{q}^{\prime}\right]} \text {. }
$$

Note that $0<P \leq 1$ if $Q-(1-q) Q_{G}^{\prime} G_{q}^{\prime} \geq \frac{1+k}{k}>0$.

Under a binding market-imposed constraint, the regulator maximizes

$$
\max _{q} V(q)=\max _{q}(1-q)\left\{1+\beta\left[1+r_{L}+\frac{(1+\bar{r})-\left(1+r_{L}\right)(1-q)}{\left(r_{H}-r_{L}\right)(1-q)}\left(r_{H}-r_{L}\right)\right](1-P Q)\right\} .
$$

From the FOC, $\frac{\partial V(q)}{\partial q}=-1-\beta(1+\bar{r}) P Q_{G}^{\prime} G_{q}^{\prime}=0$, we extract:

$$
P=-\frac{1}{\beta(1+\bar{r}) Q_{G}^{\prime} G_{q}^{\prime}} .
$$

Note that $0<P<1$ if $-\frac{1}{\beta(1+\bar{r})}<Q_{G}^{\prime} G_{q}^{\prime}$.

Under a binding regulatory constraint, the regulator maximizes

$$
\max _{q} V(q)=\max _{q}(1-q)\left\{1+\beta\left[1+r_{L}+G\left(r_{H}-r_{L}\right)\right](1-P Q)\right\}
$$

From the FOC,

$$
\begin{aligned}
\frac{\partial V(q)}{\partial q}=- & 1+A\left[-1-P Q_{G}^{\prime} G_{q}^{\prime}+P\left(Q+q Q_{G}^{\prime} G_{q}^{\prime}\right]\right. \\
& +B\left[G_{q}^{\prime}-G-q G_{q}^{\prime}-P G_{q}^{\prime} G-P Q G_{q}^{\prime}+P Q G+q P Q_{G}^{\prime} G_{q}^{\prime} G+q P Q G_{q}^{\prime}\right]=0
\end{aligned}
$$

with $A=\beta\left(1+r_{L}\right)$ and $B=\beta\left(r_{H}-r_{L}\right)$, we extract

$$
P=\frac{1+A+B\left(G-(1-q) G_{q}^{\prime}\right)}{A\left(Q-(1-q) Q_{G}^{\prime} G_{q}^{\prime}\right)+B\left[Q G-(1-q)\left(Q_{G}^{\prime} G_{q}^{\prime} G+Q G_{q}^{\prime}\right)\right]}=\frac{N(q)}{D(q)} .
$$

$P \geq 0$ unambiguously and less than one, provided

$$
1+A+B\left(G-(1-q) G_{q}^{\prime}\right) \leq A\left(Q-(1-q) Q_{G}^{\prime} G_{q}^{\prime}\right)+B\left[Q G-(1-q)\left(Q_{G}^{\prime} G_{q}^{\prime} G+Q G_{q}^{\prime}\right)\right] .
$$


Appendix B: List of variables, definitions and sources

\begin{tabular}{|c|c|c|}
\hline Variable & Definition & Source \\
\hline BANK_CRISIS & $\begin{array}{l}\text { Dummy variable for the presence of a systemic banking crisis } \\
(1=\text { banking crisis, } 0=\text { =none })\end{array}$ & $\begin{array}{l}\text { Laeven, L., \& Valencia, F. (2013). } \\
\text { Systemic Banking Crises Database. } \\
\text { IMF Economic Review, 61(2), 225- } \\
\text { 270. doi:10.1057/imfer.2013.12 }\end{array}$ \\
\hline CRISIS & $\begin{array}{l}\text { Dummy variable for the presence of a systemic banking crisis and/or } \\
\text { a sovereign debt default/restructuring }(1=\text { crisis, } 0=\text { none })\end{array}$ & $\begin{array}{l}\text { Authors elaboration from Laeven and } \\
\text { Valencia (2013) }\end{array}$ \\
\hline FFI & $\begin{array}{l}\text { Financial Freedom Index } \quad(0=\text { repressive }, \ldots, \quad 100=\text { negligible } \\
\text { government interference })\end{array}$ & The Heritage Foundation \\
\hline$G E$ & $\begin{array}{l}\text { Government Effectiveness captures perceptions of the quality of } \\
\text { public services, the quality of the civil service and the degree of its } \\
\text { independence from political pressures, the quality of policy } \\
\text { formulation and implementation, and the credibility of the } \\
\text { government's commitment to such policies. }\end{array}$ & $\begin{array}{l}\text { Worldwide Governance Indicators. } \\
\text { World Bank (2015) }\end{array}$ \\
\hline$R Q$ & $\begin{array}{l}\text { Regulatory Quality captures perceptions of the ability of the } \\
\text { government to formulate and implement sound policies and } \\
\text { regulations that permit and promote private sector development. }\end{array}$ & $\begin{array}{l}\text { Worldwide Governance Indicators. } \\
\text { World Bank (2015) }\end{array}$ \\
\hline$R \boldsymbol{L}$ & $\begin{array}{l}\text { Rule of Law captures perceptions of the extent to which agents have } \\
\text { confidence in and abide by the rules of society, and in particular the } \\
\text { quality of contract enforcement, property rights, the police, and the } \\
\text { courts, as well as the likelihood of crime and violence. }\end{array}$ & $\begin{array}{l}\text { Worldwide Governance Indicators. } \\
\text { World Bank (2015) }\end{array}$ \\
\hline $\boldsymbol{V} \boldsymbol{A}$ & $\begin{array}{l}\text { Voice and Accountability captures perceptions of the extent to which } \\
\text { a country's citizens are able to participate in selecting their } \\
\text { government, as well as freedom of expression, freedom of } \\
\text { association, and a free media. }\end{array}$ & $\begin{array}{l}\text { Worldwide Governance Indicators. } \\
\text { World Bank (2015) }\end{array}$ \\
\hline$C C$ & $\begin{array}{l}\text { Control of Corruption captures perceptions of the extent to which } \\
\text { public power is exercised for private gain, including both petty and } \\
\text { grand forms of corruption, as well as "capture" of the state by elites } \\
\text { and private interests }\end{array}$ & $\begin{array}{l}\text { Worldwide Governance Indicators. } \\
\text { World Bank (2015) }\end{array}$ \\
\hline$P S$ & $\begin{array}{l}\text { Political Stability and Absence of Violence/Terrorism measures } \\
\text { perceptions of the likelihood of political instability and/or politically- } \\
\text { motivated violence, including terrorism }\end{array}$ & $\begin{array}{l}\text { Worldwide Governance Indicators. } \\
\text { World Bank (2015) }\end{array}$ \\
\hline IQI & $\begin{array}{l}\text { Institutional Quality Index, average of the previous six institutional } \\
\text { variables }\end{array}$ & $\begin{array}{l}\text { Authors elaboration from Worldwide } \\
\text { Governance Indicators. World Bank } \\
\text { (2015) }\end{array}$ \\
\hline INF & Inflation, consumer price index (annual \%) & $\begin{array}{l}\text { World Development Indicator } \\
\text { World Bank (2016) }\end{array}$ \\
\hline$C A B$ & Current account balance (\% of GDP) & $\begin{array}{l}\text { World Development Indicator } \\
\text { World Bank (2016) }\end{array}$ \\
\hline GDPpc & GDP per capita in current US\$ (divided by 10000) & $\begin{array}{l}\text { Authors elaboration from World } \\
\text { Development Indicator. World Bank } \\
\text { (2016) }\end{array}$ \\
\hline TOP5 & $\begin{array}{l}\text { Assets of the five domestic largest banks as a share of total domestic } \\
\text { commercial banking assets }\end{array}$ & 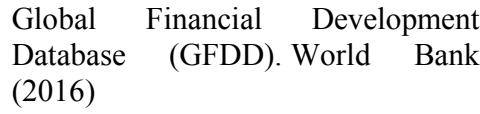 \\
\hline$B A S$ & Total assets held by deposit money banks as a share of GDP & \begin{tabular}{lcr} 
Global & Financial & \multicolumn{2}{c}{ Development } \\
Database & (GFDD). World & Bank \\
$(2016)$ & &
\end{tabular} \\
\hline MUSLIM & Percentage of Muslims on total population in 1980 & $\begin{array}{l}\text { La Porta, R., Lopez-de-Silanes, F., } \\
\text { Shleifer, A., \& Vishny, R. (1999). } \\
\text { The Quality of Government. Journal } \\
\text { of Law, Economics and } \\
\text { Organization, 15(1), 222-279. }\end{array}$ \\
\hline ENGLISH & Dummy variable: $1=$ British Common Law; $0=$ otherwise & $\begin{array}{l}\text { La Porta, R., Lopez-de-Silanes, F., } \\
\text { Shleifer, A., \& Vishny, R. (1999). } \\
\text { The Quality of Government. Journal } \\
\text { of Law, Economics and } \\
\text { Organization, 15(1), 222-279. }\end{array}$ \\
\hline $\boldsymbol{E} \boldsymbol{U}$ & Dummy variable: $1=$ European Union member; $0=$ otherwise & Authors elaboration \\
\hline EURO & Dummy variable: $1=$ Eurozone member; $0=$ otherwise & Authors elaboration \\
\hline PERIOD & Dummy variable: $1=$ year $>2007 ; 0=$ otherwise & Authors elaboration \\
\hline
\end{tabular}

